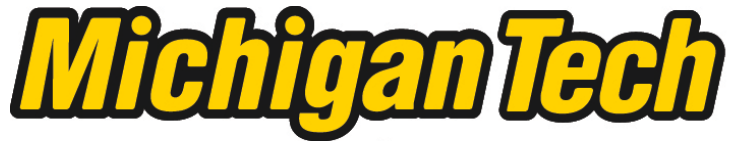 \\ Michigan Technological University Create the Future Digital Commons @ Michigan Tech
}

EPA's Council for Regulatory Environmental Modeling : a case study of science policy implementation

Genevieve M. Borg

Michigan Technological University

Follow this and additional works at: https://digitalcommons.mtu.edu/etds

Part of the Environmental Policy Commons

Copyright 2009 Genevieve M. Borg

\section{Recommended Citation}

Borg, Genevieve M., "EPA's Council for Regulatory Environmental Modeling : a case study of science policy implementation ", Master's Thesis, Michigan Technological University, 2009.

https://doi.org/10.37099/mtu.dc.etds/291

Follow this and additional works at: https://digitalcommons.mtu.edu/etds

Part of the Environmental Policy Commons 


\title{
EPA's COUNCIL FOR REGULATORY ENVIRONMENTAL MODELING: A CASE STUDY OF SCIENCE POLICY IMPLEMENTATION
}

\author{
By \\ GENEVIEVE M BORG \\ A THESIS \\ Submitted in partial fulfillment of the requirements \\ for the degree of \\ MASTER OF SCIENCE IN ENVIRONMENTAL POLICY \\ MICHIGAN TECHNOLOGICAL UNIVERSITY \\ 2009
}

Copyright (C) Genevieve M Borg 2009 
This thesis, "EPA's Council for Regulatory Environmental Modeling: A Case Study of Science Policy Implementation," is hereby approved in partial fulfillment of the requirements for the Degree of MASTER OF SCIENCE IN ENVIRONMENTAL POLICY.

\section{DEPARTMENT:}

Social Sciences

Signatures:

Thesis Advisor

Carol MacLennan

Department Chair

Patrick Martin

Date 


\section{Table of Contents}

Abstract

Chapter 1: Introduction ........................................................... 3

1.1 Science Policy and CREM $\quad 5$

1.2 Research Goals $\quad 8$

1.3 Methods 9

1.4 Summary 12

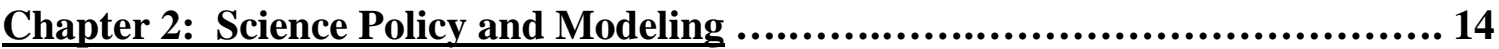

2.1 Introduction to Science Policy 14

2.2 Uncertainty 16

2.3 Regulatory Versus Research Science $\quad 18$

2.4 Organizational Issues 21

2.5 Implementation $\quad 25$

2.6 Modeling 27

2.7 Model Use at EPA and Other Federal Agencies 32

2.8 Conclusions 36

Chapter 3: Council for Regulatory Environmental Modeling ....................... 38

3.1 History of Modeling Policy at the EPA 38

3.2 Origins of the CREM $\quad 41$

3.3 Models Knowledge Base $\quad 48$

3.4 NAS Report

3.5 Guidance Document 53

$\begin{array}{ll}3.6 \text { Conclusions } & 57\end{array}$

Chapter 4: Impediments to Implementation ..................................... 58

4.1 Introduction $\quad 58$

4.2 Classic Impediments $\quad 59$

4.3 Implementation Paradoxes 64

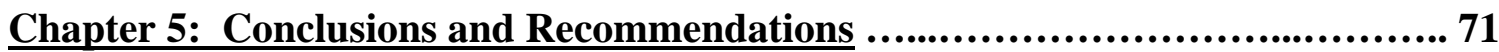

$\begin{array}{ll}5.1 \text { Conclusions } & 71\end{array}$

$\begin{array}{ll}5.2 \text { Recommendations } & 73\end{array}$

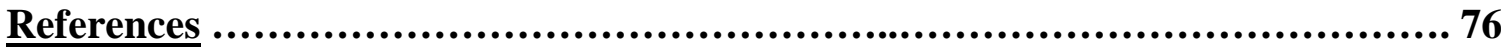

Appendix A - Interview Questions

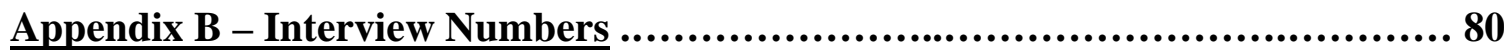

Appendix C - EPA Organization Charts $\ldots \ldots \ldots \ldots \ldots \ldots \ldots \ldots \ldots \ldots \ldots \ldots \ldots \ldots \ldots \ldots \ldots \ldots . . .61$ 


\begin{abstract}
:
As environmental problems became more complex, policy and regulatory decisions become far more difficult to make. The use of science has become an important practice in the decision making process of many federal agencies. Many different types of scientific information are used to make decisions within the EPA, with computer models becoming especially important. Environmental models are used throughout the EPA in a variety of contexts and their predictive capacity has become highly valued in decision making.

The main focus of this research is to examine the EPA's Council for Regulatory Modeling (CREM) as a case study in addressing science issues, particularly models, in government agencies. Specifically, the goal was to answer the following questions: What is the history of the CREM and how can this information shed light on the process of science policy implementation? What were the goals of implementing the CREM? Were these goals reached and how have they changed? What have been the impediments that the CREM has faced and why did these impediments occur? The three main sources of information for this research came from observations during summer employment with the CREM, document review and supplemental interviews with CREM participants and other members of the modeling community.

Examining a history of modeling at the EPA, as well as a history of the CREM, provides insight into the many challenges that are faced when implementing science policy and science policy programs. After examining the many impediments that the CREM has faced in implementing modeling policies, it was clear that the impediments fall into two separate categories, classic and paradoxical. The classic impediments include the more standard impediments to science policy implementation that might be found in any
\end{abstract}


regulatory environment, such as lack of resources and changes in administration.

Paradoxical impediments are cyclical in nature, with no clear solution, such as balancing topdown versus bottom-up initiatives and coping with differing perceptions. These impediments, when not properly addressed, severely hinder the ability for organizations to successfully implement science policy. 


\section{Chapter 1: Introduction}

As environmental problems became more complex, policy and regulatory decisions become far more difficult to make. The use of science has become important in the decision making processes of many federal agencies. This has given rise to many controversies about the appropriate way to incorporate science into these important decisions, and who should decide what constitutes "good science”. The Environmental Protection Agency (EPA), a regulatory agency, is often at the center of this controversy and must implement policies that address these issues. Many different types of scientific information are used to make decisions within the EPA, with computer models becoming especially important.

Environmental models are used throughout the EPA in a variety of contexts and their predictive capacity has become highly valued in decision making. Some of the more common models deal with air and water quality, such as fate and transport modeling. For example, with an air pollution fate and transport model, a user enters input factors such as atmospheric patterns, terrain conditions and type of pollutants and the model would provide an output such as estimates of the ultimate fate of the pollutants, and how they would travel to that final location.

However, models bring about many issues that need to be addressed in order to justify their use in the policy arena. Most of these issues reflect larger debates over uncertainty and peer review of science used in policy. The Council for Regulatory Modeling (CREM) is a science policy program developed at the EPA in 2000 to guide agency modeling activities, and to ensure that the models being used incorporate the best available science. 
The main focus of this research is to examine the CREM as a case study in addressing science issues, particularly models, in government agencies. Implementing policies or guidance on the use of models is of the utmost importance when dealing with regulatory decision making. It ensures that all models used in a particular decision based on solid science. It can also ensure that the process used to deem something as "good" science and appropriate for a particular decision is transparent to the public. CREM is an example of a program that was created within the EPA to address these issues with a focus on continuous improvement of modeling practices throughout the agency. Since modeling inevitably involves a level of uncertainty, it is important that models be evaluated to ensure that they represent "good science." This is especially important when they are being used for regulatory decisions, since they may be vulnerable to legal scrutiny.

The CREM provides an interesting case study since it was established to deal with modeling issues as a whole and is the first program created within a government agency that provides general guidance on a wide range of regulatory environmental models, from development to use. When implementing this type of policy in an agency such as the EPA, many impediments arise. Looking at the impediments to the Council's regulatory modeling policy and their effect upon the goals of consistency and transparency provides insight into other cases of policy implementation in other federal agencies.

Because of the numerous issues involved in appropriate use of models in the EPA, the question arises as to whether or not the CREM has been successful in creation of a comprehensive and consistent policy for the use of models in decision making. Further, what will its role be in the future as models become more necessary for larger, more 
complex environmental problems? These questions are important since models are becoming a key component of science that is used not only within the EPA but throughout federal agencies. As we face more complex regulatory issues, it is inevitable that these agencies will continue to become more dependent on the predictive value of models. Since the CREM is the first program developed within these agencies to develop modeling guidance, a thorough examination of its strengths and weaknesses could provide insight into the larger questions surrounding of the use of models in regulatory agencies.

\subsection{Science Policy and CREM}

Science policy is a broad term that encompasses many different levels and types of scientific decision making. There are two main ways to look at science policy. The first is the use of science in policy. The second is the management of science used in policy to ensure that the science that is used is of the utmost quality. The CREM is a good example of managing the use of science through continuous improvement processes. It was created in order to ensure that the information obtained from models in the EPA (including information used to make regulatory decisions) is transparent and has the lowest possible level of uncertainty. It also promotes consistency throughout the modeling community by establishing best practices that should be used throughout the lifecycle of a model (creation, use and application).

Inevitably, using science in decision making can cause controversy. Some of the most important discussions within the science policy field are about uncertainty, regulatory versus research science, bias and the role of the scientist, and the role of 
science advisory committees. All of these issues are important when looking at the use of models in regulatory decision making as well and will be expanded on in Chapter 2.

One aspect of science policy that has not drawn much attention in the literature, but is very important to this research is implementation of science policy, especially at the "meso" level (a term referring to programs and policy that apply within federal agencies). The two main issues that will be discussed are how organizational structure affects implementation and the strengths and weaknesses of different implementation strategies. The CREM faces organizational issues with the organization of the EPA as a whole, as well as the organization of the CREM itself. The CREM is organized so that it includes staff members (currently one) that are dedicated completely to the CREM, a Council made up of senior management from each program and regional office, and a workgroup that consists of scientists and modelers from every program and regional office (EPA, 2009).

Regulatory environmental modeling is an important aspect of EPA's science policy. However, models come with their own set of issues that must be addressed, many of which are parallel to the problems that exist with any type of science. The main issues that the CREM attempts to address are uncertainty, transparency and uncertainty. Societal groups who suffer the negative impacts of regulations often challenge them based on the appropriateness of the science used in the process, addressing these issues may help to avoid legal challenges from these groups. To overcome these legal challenges, the EPA often relies on science advisory committees and the implementation of science policy programs, such as the CREM, to ensure that models are based on good, unbiased information that is appropriate for use in regulatory decisions. 
The CREM was developed after a long history of the EPA's Science Advisory Board reviewing individual models, and ultimately making the same recommendations about the need for better model evaluation and validation every time. Up until this point, there was no recognition of the need to address modeling issues as a whole. Two important pieces of legislation have impacted the use of models in regulatory decision making, and have been large motivators to the development of the CREM. The first is the Administrative Procedures Act that designates how federal agencies develop rules and the process the courts use to challenge these rules. The second piece of important legislation was the Data Quality Act. The Act required that all federal agencies develop their own management guidelines and procedures in compliance with OMB (Section 515 of the Treasury and General Government Appropriations Act, 2001). Both of these pieces of legislation are noted as being substantial factors in the creation of the CREM as well as factors that provided impetus for many of the CREM's actions. A full history of the CREM is provided in Chapter two, including information on the CREM's three main projects: The Models Knowledge Base, The NAS report and the Guidance Document.

Today, the CREM is focused on three activities: completing the revised guidance document, responding to the NAS report, and developing workshops for EPA employees on integrated modeling. The guidance document went out for a 30 day public comment on August 13, 2008, and the final draft is currently being written. Two workshops were planned for late 2008. The first would have addressed the NAS report, focusing on, how to respond to their and on development of and agency-wide plan. However, due to lack of participation, this workshop was cancelled. The other conference was held and 
focused on issues surrounding integrated modeling and how the CREM can help facilitate activities.

\subsection{Research Goals}

I examined the Environmental Protection Agency’s Council for Regulatory Modeling as a case study of science policy implementation. The CREM itself represents part of a science policy that the agency has implemented in order to address various issues that arise with regulatory environmental modeling. The case study offers insight into the types of issues surrounding science policy in regulatory agencies and highlights possible, perhaps unavoidable, impediments to implementation.

Specifically, my research attempts to answer the following questions: What is the history of the CREM and how can this information shed light on the process of science policy implementation? What were the goals of implementing the CREM? Were these goals reached and how have they changed? What have been the impediments that the CREM has faced and why did these impediments occur?

A history of modeling and its use at EPA make it clear that issues surrounding regulatory modeling are important science policy issues. Until CREM was initiated, there were multiple efforts to address the use of models. However, there was little consensus in the EPA on how to address the issues that models posed, and therefore nothing was accomplished. The main purpose of the CREM is to address these issues and to promote better practice, most often through guidance activities. Whether or not this guidance is followed, and to what extent, is harder to determine. Therefore the success of the CREM can be looked at from multiple perspectives: have they offered 
clear and comprehensive guidance, have they exploited every avenue to ensure that EPA model creators and decision makers are aware of and understand the guidance (guidance documents, workshops, meetings, etc), and to what extent is this guidance being followed throughout the agency?

This research offers a perspective on science policy implementation at the "meso" level by focusing on regulatory modeling. Often, when agencies develop a new science policy, the policy is reviewed by a group of science experts such as the SAB and perhaps a group of policy experts as well. However, these reviews are more focused on the content of a policy instead of the process. For example, the SAB reviewed the CREM's guidance document on how well it addressed modeling issues and whether they offered acceptable best practices. However, they did not examine whether or not the CREM had a feasible plan to implement the best practices. Reviewing how an agency implements a science policy gives information on the impediments that science policy implementation faces that can ultimately prevent a policy from being successful. Having good scientific guidance is irrelevant if it cannot be successfully implemented.

\subsection{Methods}

The main sources of information used in this research were observations in the science policy office at EPA, agency documents, and semi-structured telephone interviews. Employment at EPA in the CREM office during summer of 2008 allowed me to observe the office dynamics and project activities. My duties during my employment included updating the Models Knowledge Base and compiling a database of models appropriate for use in regional decision making activities. Throughout this time, I was 
able to observe a number of different CREM meetings of the work group, of small groups of Council members, and of individuals in the Office of the Science Advisor. During these months I also observed the interactions of agency employees as they completed the guidance document. This included my own interactions with CREM members and agency employees in my day to day duties. I also had contact with various CREM workgroup members in my work updating the Models Knowledge Base. These observations provided me with valuable insight into how the CREM works, how agency staff responded to requests from the CREM, and how involved various Council members were in the mission of the Council. These observations and interactions motivated me to further pursue the CREM as a science policy case study.

My review of EPA materials included a wide range of documents related to the CREM and to modeling in general. A majority of the documents that provided information on the creation of the CREM were memos written to and from the Administrator. These memos provided information about when and why modeling issues became a concern within the agency and how these issues should be addressed. Included were the memos that suggested that the Agency take notice of the modeling issues, that a workgroup (ATFERM) be created to address the issues, that the CREM be created, and that the CREM be charged with such tasks as creating the Guidance Document and the Models Knowledge Base (among other things).

I also read multiple reports concerning modeling, starting with documents from the 1980s. Most of the earlier reports addressed issues from a particular model, or a particular type of model. These reports provided information on why the various modeling issues became cause for concern. Other reports, such as reports that laid out 
the Framework for the CREM, SAB reviews on CREM activities, the NAS report on regulatory modeling and the Guidance Document were reviewed with more scrutiny than earlier reports because they provided more insight into the goals and success of the CREM. Extra attention was paid at analyzing the guidance document since this is seen as the main product of the CREM. I also examined all available meeting minutes in order to analyze some of the discussions that occurred at various CREM meetings which provide valuable insight into the early decisions, such as whether or not the CREM would play the role of the "model police".

The document review was then supplemented by conducting semi-structured telephone interviews with members of the CREM and other agency employees who work with models, but are not necessarily a part of the CREM. This part of my research underwent a human subject review and was approved for a period of one year (protocol \# M0367). The purpose of these interviews was to understand how the goals of the CREM have changed and whether or not there was consensus throughout the group as to what the actual goals were. These interviews also provided insight into why workgroups members chose to, or chose not to, be involved with the projects of the CREM. For example, some workgroup members worked on authoring the Guidance Document while others only provided input when asked to specifically do so. The interviews also gave an opportunity to examine what different members see as the future of the CREM, and if that differs from what they would like to see as the future of the CREM. They were also able to state whether or not the work of the CREM has been directly beneficial to them, and if not what could be done differently in order to be more useful.

A second set of interviews was conducted with agency employees who worked 
with models, but who were not actual members of the CREM (although they may have worked with the CREM in some capacity at one time or another). The purpose of these interviews was to get a sense of how the CREM is viewed throughout the modeling community (within the agency). They provided information on how involved nonmembers are with the CREM and whether they find the work of the CREM to be helpful. In particular, these interviews provided information on how useful the guidance document has been or will be to the modeling community.

All three sources of information provide useful information for examining the CREM as a science policy implementation case study. Working within the CREM allowed for firsthand experience and observations which became the basis for this project. The documents provided concrete information about what the CREM has done and why. The interviews then provided supplemental information that explained the events surrounding the work of the Council and documents prepared, the types of problems that arose, and how the CREM has been viewed within the agency.

\subsection{Summary}

Successful implementation of science policy is essential in order to have the best possible scientific information to use in regulatory decisions. In order to understand science policy implementation, it is important to understand the broader issues that are faced, such as uncertainty, problems specific to regulatory science, and the role of organizational structure. The CREM is unique since it is the first federal agency program created to provide comprehensive guidance on regulatory model development and use, The fact that an entity such as the CREM has even been developed is a huge 
accomplishment in the federal government, and the lessons learned from the process will be important as other agencies develop more comprehensive modeling guidance as well.

The organization of this thesis is as follows: The second chapter will look in depth at science policy and modeling and implementation of policies and programs. The third chapter will thoroughly examine the Council for Regulatory Modeling, including how it originated, what it has done since then and what have been the major events that have led to CREM actions and initiatives. Chapter four outlines the major impediments to implementation that the CREM has faced. Finally, Chapter five offers conclusions that relate this research to previous research on science policy implementation as well as recommendations for the CREM and for science policy implementation in general. 


\section{Chapter 2: Science Policy and Modeling}

\subsection{Introduction to Science Policy}

The term science policy encompasses a broad range of decision making activities that employ science as an aid in the process. These decisions can range from risk assessment activities to homeland security assessments to air and water pollution issues. Inevitably, as the field of science has changed, so has the scope and definition of science policy. Very generally, it is described as an area of decision making in which science plays a role in regulatory proceedings (Jasanoff, 1990). A more in depth definition is given by Smith (1990), "Science Policy is concerned with the promotion of scientific discovery and technological innovation, the regulation of potentially harmful side effects resulting from their application, and the coordination of politics and programs within the government and in society to achieve the appropriate balance between nurture and restraint.” This second definition alludes to how science policy can encompass not only the use of science in policy, but also policy that regulates the science itself. It is important to look at science policy in both ways to fully understand the issues that occur with programs such as the CREM (which is an example of implementation of science policy within the EPA).

The EPA is not the only federal agency that faces science policy challenges. Two other agencies that also deal with issues of human and environmental health are the Food and Drug Administration (FDA) and the Occupational Safety and Health Administration (OSHA). Both of these agencies also fall subject to the same type of scrutiny as the EPA. In a study of decision making at EPA and OSHA, Ted Greenwood found that while many regulatory agencies are thought to be scientifically incompetent, it is 
institutional factors rather than lack of scientific competence that leads to perceived failures (Greenwood, 1984). Regulatory agencies often require information to make a decision that is just not known, and therefore have to rely on discretion rather than certainty (Greenwood, 1984). This leaves them vulnerable to legal challenges, especially under the Administrative Procedure Act which states that agencies cannot make decisions that are "arbitrary and capricious" or not properly supported with "substantial evidence" (Jasanoff, 1990). This type of vulnerability is especially relevant when using models. Implementing science policy within an agency can address many of the issues that surface when using science in policy, such as uncertainty and bias. While implementing science policy can help to address issues such as uncertainty, it presents a new set of issues. These issues include addressing the differences between research and regulatory science and organizational issues. A final aspect of science policy as a whole is the role of science advisors, both in reviewing the science that is used in policy as well as the level of influence that they should have on the implementation of science policy.

While it is important to understand some of the basic principles and problems associated with science policy, for this research it is important to also examine more fully the use of models in federal agencies, and the problems and subsequent policies associated with this use. The EPA uses a very broad range of model types. However, it is not the only agency that relies on models. The Food and Drug Administration and the Department of Transportation are two examples of other agencies (one regulatory, one not) the use models as well. Since federal agencies tend to face the same organizational and political challenges, understanding the history of model use and policy at the EPA, as well as the impediments faced by the CREM in implementing these policies, can be 
beneficial to preventing these issues from occurring at these other agencies as well.

\subsection{Uncertainty}

Inevitably, using science in decision making can bring about controversy. Science always includes a level of uncertainty, therefore making it vulnerable to scrutiny, especially when it is being used to make important choices within the government. Because of this uncertainty, there is controversy over how and to what extent science should play a role in regulatory decision making (Pielke, 2007). Decisions must be made over how much uncertainty is acceptable when using science as the basis for a decision. This can often create tension between science and policy since the level of uncertainty acceptable in each is often very different (Kinzig and Starrett et al, 2003). In science it is crucial to have the most accurate information from which to build policy. However, in policy making it is sometimes more important to have a timely decision rather than making the effort to ensure the most accurate information (Kinzig and Starrett et al, 2003). Finding the appropriate balance offers a significant challenge. Implementing effective science policy can bridge the gap between the two and ultimately provide “good” science in a timely manner.

Given that uncertainty is irreducible in some cases (Pielke, 2007), best estimate methods must be used that cannot avoid value judgments, errors and biases (Andrews, 2006). These are issues that have to be addressed in order for science to be considered "good” science. That is not to say that uncertainty must be eliminated, since as previously mentioned this is most often impossible. However, it must be demonstrated that the uncertainty is taken into account. It also must be demonstrated that there was an 
obvious effort to eliminate the influence of values and bias in the use of science.

Since uncertainty is inevitable in most cases, care must be taken to reduce uncertainty as much as possible, and to account for it when it cannot be reduced any further. There are many different steps that can be taken to ensure that science used in a decision making process is "good” science. Many of these steps can be addressed with good science policy programs, such as the CREM. One step is to require a peer review for "regulatory" science (Jasanoff, 1990) in order to eliminate the infiltration of value judgments and biases. Part of the model evaluation process that the CREM addresses is ensuring that models are properly peer reviewed before they are used in regulatory decisions.

Another, probably the most common, method to ensure "good science" is to utilize science advisory committees whose purpose is to provide disinterested recommendations concerning the use of science in decision making (Compton, 1936). Science advisory committees can make two types of recommendations: 1) about the use of science in policy; and 2) about how to handle science policy issues as they pertain to particular topics. For example, the EPA's SAB will provide reviews of particular models to ensure that they are appropriate for a particular regulation. However, they also provide general recommendations on how to address modeling issues as a whole. It is possible that without the recognition of modeling issues by the SAB, science policy dealing with these issues (such as the policies and guidance created by the CREM) would not exist today.

Environmental modeling is an interesting case study to examine how science policy addresses uncertainty because it is inherent that models will have uncertainty in 
their outputs. They are, by definition, only a representation of the real world (EPA, 2008). Since models are inevitably uncertain, transparent evaluation must occur in order for them to appear appropriate in the decision making process. It is obvious that there needs to be some sort of science policy that addresses the issue of uncertainty in modeling. The CREM was therefore created to address these issues. It provides guidance to model creators about how models should be developed and how to evaluate the models in order to understand the level of uncertainty that exists for a particular model. It also provides guidance to decision makers on how to use a model properly based on the level of uncertainty to ensure it is appropriate for the decision. Providing guidance to everyone that deals with a model ensures that 1) uncertainty will be decreased to the greatest extent possible and 2) the level of uncertainty will be transparent and communicated so that people using the model outputs can make appropriate decisions based on the output.

\subsection{Regulatory Versus Research Science}

One of the controversies that arise within science policy is the use of what has been labeled "regulatory science” (which has also been referred to as mandated science) - a concept contrasted with "research science”. There is a difference between openended original research and research that is done to serve a regulatory purpose (Jasanoff, 1990). Some suggest that there is nothing wrong with conducting science for regulatory purposes, as long as it is kept completely separate from the decision making process (Irwin et al, 1997). However, it is seldom that the two are kept completely separate, which causes problems. As the name suggests, the CREM was intended to focus on 
regulatory modeling. However, it is difficult to determine where that line needs to be drawn. Will a model that is considered a research model right now be used for a regulatory decision in the future? The CREM therefore has to implement policy that addresses the issues which occur in regulatory science, but which can also be applied to research science as well.

There are several problems with regulatory science that are important to the discussion of science policy. One problem is that there are often preconceptions of what policies should look like before the incorporation of scientific information. As a result, the science may become distorted in such a way that it agrees with these preconceptions. For example, if the EPA wanted to make air pollution regulations more stringent, they might seek out only the scientific information that supports this decision. This may lead to the agency using "bad" science simply because it fulfills a need.

A second problem is that value judgments can be more prevalent in regulatory science than in research science. Conducting scientific activities for the sole purpose of regulatory decision makes it no longer just about the science and allows for bias if there is too much influence from industry and the government. This bias can invalidate a decision in the eyes of the public (Jasanoff, 1990). For example, if a model user decides to use the outputs from a model as inputs for a different model instead of real world data, this is a judgment that could be viewed as biased by the public.

A third issue with regulatory science is the gap between the level of uncertainty acceptable in regulatory and in research science (Kinzig and Starrett et al, 2003; Alario and Brun, 2001). There are two views on this subject, with one claiming that it is more important to reduce uncertainty in research science (Kinzig and Starrett et all, 2003) and 
the other claiming that it is more important to address in regulatory science (Alario and Brun, 2001). The first claim asserts that it is of the utmost importance in scientific research to reduce uncertainty as much as possible to diminish the risk of basing further research on inaccurate information, however, when making policy decisions, it is often more important to make a timely decision with the best available information (therefore reducing uncertainty is not always feasible) (Kinzig and Starrett et al, 2003). The second claim, however, points out that uncertainty is generally more criticized in regulatory science since the results are most likely going to be used to make a regulatory decision (Alario and Brun, 2001). In "pure science” on the other hand, there is less emphasis on being certain and more on exploring possibilities (Alario and Brun, 2001).

The two conflicting views on how much uncertainty is considered acceptable pose a challenge for science policy, such as that at EPA, which deals with an overlap of regulatory and research science. On one hand, you want to make a timely decision, so you may not want to focus too much on issues of uncertainty. However, if you neglect uncertainty, you will be subject to more scrutiny from the public since it is the basis of a regulation. This, in turn, could lead to legal challenges which could reverse a regulatory decision (McGarity and Wagner, 2003). The CREM has to determine a specific level of uncertainty acceptable in each type of models used in the agency in order to avoid legal repercussions. They also must determine whether or not there should be a difference in the acceptable level of uncertainty if the model is created for regulatory or research purposes. Ultimately, this creates a significant impediment to the implementation of science policy by the CREM, since it may be impossible to address models that fall somewhere in the middle of regulatory and research purposes 
The types of problems with regulatory science discussed above indicate that it is fundamentally different from research science and as such, requires different criteria for evaluating its utility and validity. Jasanoff (1990) argues that since regulatory science is subject to infiltration of values and biases, it should be subject to more intense peer review in order to ensure that those values and biases are not compromising the integrity of the science being used in the decision.

\subsection{Organizational Issues}

The role of organizational structure and behavior is important to consider when implementing science policy. In particular it is important to look at the role that scientists and science advisory committees play in these organizations as well as how the organizations (such as the EPA) are structured.

When looking at organizational issues, it is important to discuss the role of the scientist. The role of the scientist in science policy can often determine whether or not the science is "good". Scientists can choose to play different roles and present scientific information in a way that promotes their own values (Pielke, 2007). Some may choose the "pure science" route working to keep their values separate from the decision making process and trying to provide unbiased scientific information. Others may choose to play the role of the "issue advocate" and encourage certain choices over others based on their own values (Pielke, 2007). It is important to consider the situation when determining the role that the scientist should play.

Modelers (including model creators and model users) have many opportunities in which they can allow their own values and biases to influence an outcome. Model 
creators often face the difficult decision of what assumptions to use as the basis for a model. Assumptions should be based on the best possible data and information. However, often the data available is inadequate so model creators must use their best judgment in determining the assumptions, and often they have to make a value judgment. Also, model users are often faced with the same dilemma in determining the model inputs. For example, when given a range of pollution levels from a given facility, they may choose to use a pollution input that is on the higher side if they want to show that the facility is causing a lot of damage to the environment around it.

Another important aspect of the organizational structure of science policy programs is the role of science advisory boards. One of the common ways that agencies have dealt with these issues of scientific uncertainty and the possibility of "bad" science resulting in bias is through use of science advisory committees. These committees consist of external scientists (most often experts in a relevant field) that guide decision makers on how to most appropriately use scientific information, or in some cases, to do research and provide the scientific information themselves (Jasanoff, 1990). The original goal of science advisory committees is to provide the Federal Government access to scientific advice that is competent yet disinterested (Compton, 1936). In other words, the Federal Government needs to have sources of advice that can be seen as scientifically legitimate, as well as free from any bias by industry or the government itself. The three earliest groups that were constructed (the first as early as 1863) were the National Academy of Sciences, the National Research Council and the National Science Advisory Board (Compton, 1936). All three still exist today.

The success of science advisory committees throughout their lifespan has been 
mixed. Two issues stand out. The first is that science advisory committees are criticized for not being sufficiently balanced (in terms of citizen membership) and for imposing too much influence on the decision making process (Ashford, 1984; Jasanoff, 1990; GAO, 2001). These issues were addressed in 1972 under the Federal Advisory Committee Act (FACA). In 2001, the General Accounting Office (GAO) issued a report assessing the current policies and procedures of EPA's Science Advisory Board to ensure that its peer review panelists are independent and balanced and that the public is provided with sufficient information on the points of view of panel members (in order to provide transparency) (GAO, 2001). Overall, the GAO found that the procedures followed by the EPA were severely lacking. For example, they found that the agency did not identify relevant conflict-of-interest requirements and that no systematic process exists for balancing panels (GAO, 2001).

The second issue that arises is that scientific committees can have the ability to influence the decision making processes. There is a delicate balance that must be maintained between advice and decisions. There are frequent claims that advisory bodies have too much influence on decisions (Jasanoff, 1990). At other times, agencies are criticized for not following the advice and recommendations of the advisors (Jasanoff, 1990). Often, it is difficult for advisory committees to maintain complete independence from agencies as the government has control over the membership, scope and financial support of these committees (Pursell, 1965). When committees are not properly supported by their parent agencies, it is difficult for them to perform the way they are expected to (Ashford, 1984). In the case of the CREM, the Science Advisory Board has played an important role in bringing modeling issues to the attention of the agency. The 
SAB's original comments about modeling issues were ignored by the administration. However, it was their persistence and dedication to solving these issues that ultimately led to the creation of the CREM.

The structure of an organization can have a large impact on its success as well. The EPA is organized into different program offices and regional offices (see Appendix C). Each office has its own assistant administrator, which is a politically appointed position. The CREM is housed in the Office of the Science Advisor (OSA), which is not technically considered a program office (yet), but is a subsector of the Office of Research and Development (EPA, 2009). The politically appointed position at the head of the OSA is the Science Advisor. The CREM answers directly to the Science Advisor and the Science Policy Council (which is also located in the OSA) (EPA, 2009). This location poses some issues for the CREM since there is no direct line between the OSA and the other program and regional offices, and the Science Advisor does not have authority over any of the other offices (the Science Advisor, like the assistant administrators, answers to the administrator).

The structure of the CREM tries to address this disconnect through its own organizational structure. The Council is made up of one (sometimes two) members from every program and regional office (and one member that serves as a liaison between the CREM and the SAB). This allows for the CREM to connect with all of the offices, and theoretically gain the support from the assistant administrators. However, this structure poses additional issues for the CREM, such as finding the balance between the regional and program offices and dealing with one member representing a whole office. 


\subsection{Implementation}

There has not been much research into the implementation of science policy programs at what is deemed as the "meso level”, or a middle level that would include government agencies such as the EPA (Rip, 1987). However, there has been research done on larger level national programs that may shed light on the implementation of smaller science policy programs such as the CREM. The discussion of science policy program implementation includes the use of “implementation structures” and “implementation gap” and also examines the different types of implementation strategies. Implementation structures can be defined as “a multi-organizational unit of analysis, which horizontally connects, through network linkages, a cluster of (parts of) public and private organizations involved, usually through consensual self-selection, with the implementation of the program” (Nederhof, 1989). Within an implementation structure there will be differing goals and objectives of the various actors that may or may not be match the goals of the program itself (Nederhof, 1989). While on the scale of national programs these implementation structures include private and local scale organizations, and the CREM currently does not, it is a concept that could be applied to a program such as the CREM.

The implementation gap is an important subject to consider when discussing the implementation of any type of policy program. It is the concept that there is a gap between policy objectives and policy realization where implementation is the main concern (Nederhof, 1990). While this concept seems rather obvious, it was not always the case with science policy since originally science patronage was focused on allocation of funds instead of attainment of goals (Nederhof, 1990). With the CREM, the 
implementation gap has definitely occurred. For example, one of the main goals of the CREM has always been to create general guidance on modeling to be implemented throughout the agency. While the guidance itself is complete, how to implement it is a growing problem. Therefore, there is a gap in meeting the objective of creating the policy and the realization of the policy throughout the agency.

A last notion that is beneficial to consider is the different types of implementation strategies that have been studied. There are two different debates found in the literature that are relatable to the CREM: top-down versus bottom-up and "orchestrating” versus "accommodating.” While there may be some overlap of the definitions of the strategies in the differing debates, it is important to consider both since they can each offer insight into the CREM's implementation strategy (or lack of).

The top-down versus bottom-up debate looks mainly at the differences in flexibility. A purely bottom-up implementation strategy will rely on the scientists to more or less set the priority and involves policy that does not limit the scientists (Nederhof, 1990). In terms of modeling, this type of an approach would allow for the model creators to make guidance decisions. In contrast, a strictly top-down implementation does not allow for flexibility if there are problems at the lower level that could not have been predicted.

The "orchestrating” versus "accommodating” strategies (categorized as such by Rip and Nederhof, 1986) are ways of dealing with the issues that arise from the purely top-down or bottom-up implementation approaches. "Orchestrating” strategy could be viewed as a less extreme top-down approach. It is "a strategy, characterized by policy makers' selective development of activities in order to take the (implementation) 
situation into account, as well as occasional adaptation to the situation (of the policy maker) in order to realize his own goals” (Rip and Nederhof, 1986). So while this is still a relatively top-down approach, where the policy makers’ goals are the priority, it is slightly more flexible to the implementation process. The “Accommodating” strategy, on the other hand is guided more by what is going on in the field. In this strategy, the policy maker may sometimes attempt to make changes to meet their own goals, but for the most part they adapt to what is seen as important in the field (Nederhof, 1990).

\subsection{Modeling}

Before one can understand the CREM and the problems it faces, it is important to have at least a basic understanding of what a model is and why they are used. There are many different definitions of a model. Broadly, modeling is any process or structure that is meant to represent a real world scenario. However, the National Research Council report uses a definition more appropriate for this research: “A simplification of reality that is constructed to gain insights into select attributes of a particular physical, biological, economic or social system” (NRC, 2007). Models are particularly important when dealing with environmental issues since most often, due to a lack of financial resources, it is not possible to take real life measurements (CREM, 2008). Instead, models can be used to make predictions in a more affordable and timely way.

Currently, the models that are used within the EPA are primarily computer models in which a model creator creates a computer code to run a mathematical algorithm. The model will have a particular set of inputs, preferably actual measurements but sometimes they are data derived from outputs of other models. When 
the user inputs the necessary information, the model will run the information through an algorithm that is designed to make the best possible prediction. The algorithm will then provide output containing the information necessary to make a decision.

An example of a model utilized within EPA is the AQUATOX model, that simulates an aquatic environment by tracking the fate and transport of pollutants and predicting the effects they will have on an ecosystem. It does this by simulating the transfer of energy, biomass and chemicals (Models Knowledge Base, 2009). AQUATOX is an interesting example because it is a proprietary model - a model that is used by the EPA but was not developed by the agency. With a proprietary model it is most important for agency staff to follow the agency guidelines for its use. This ensures that the model is of the highest quality and is as transparent as possible.

The inputs to the AQUATOX model include water body loadings, site characteristics, chemical characteristics of organic toxins and the biological characteristics of plants and animals in the ecosystem. The model then outputs the timevarying biomass of plants and animals, chemical and organic toxin concentrations in water, organic sediments and biota (Models Knowledge Base, 2009). While this model is seen as quite complex (multiple output variables are involved), it is created in such a way that the user does not have to have programming knowledge in order to use it. The only knowledge necessary is a basic understanding of biology and/or ecology (Models Knowledge Base, 2009). As a result, it is relatively easy for outside stakeholders to run the model with their own information and see if the results that they get are comparable to the results that the EPA is using to make decisions. 
AQUATOX has been thoroughly evaluated by the creator as well as by the EPA employees that work with the model to ensure the quality of the outputs. The equations used for this model were derived from previous water quality models and peer reviewed literature, and the accuracy of the code was verified on a line by line basis by the model programmer. The outputs of the model are also validated against observed conditions to ensure that the model predictions are comparable to what is actually occurring. The information in the Models Knowledge Base points out, however, that it is impossible to rigorously validate all of the output variables against real world conditions since there are multiple output variables, and the observed data is not necessarily available (Models Knowledge Base, 2009).

EPA staff face three major problems when applying models such as AQUATOX to regulatory decision-making: uncertainty, transparency, and consistency.

Uncertainty. The issue of uncertainty is common in use of AQUATOX and other models, as they are only predictive tools. Uncertainty is sometimes a product of the algorithm created for the model, and it is not possible for the algorithm to make a perfect prediction based on the inputs provided. Therefore, model users prefer that equations used with specific models come from peer reviewed literature or from other evaluated models viewed as legitimate. The algorithms used for the AQUATOX model come from both sources.

Uncertainty is also a product of the input information as well. While it is preferable that the inputs are real life measurements, such as actual real world water body loadings for the AQUATOX model, these measurements are not always readily available, and therefore outputs of other models need to be used (Interview \# 12, 2009). These 
outputs obviously include a certain level of uncertainty and this transfers into the inputs to the new model. It is important to understand that this transfer can occur and to account for it in the decision making process. If, for example a decision maker is using information from a model to make a decision, it is essential that they understand all of the unknowns that are associated with the output in order to justify its use in the decision. For example, if the user does not inform a decision maker that the inputs used were predictive instead of actual, then the decision maker does not have all of the information necessary to make an informed decision. This can lead to a controversy over whether or not a regulation is based off of sound information and therefore legitimate.

Transparency. Transparency is a second issue regulators must address when applying models to regulatory decisions. Scientists and the public outside of the agency should be able to run the model with their own data and confirm that their results agree with those of the agency (Interview \# 2, 2009). Further, the entire process of developing, evaluating and utilizing the model should be transparent and easily available to the public. This validates whether or not a particular model was an appropriate choice for the task, and allows for an evaluation as to whether the results provided by the model are a proper fit with the decision to be made. When there are gaps in transparency, the opportunities for legal action against a proposed regulation are greater (Interview \# 2, 2009). Transparency in models is provided by adequate documentation of all aspects of how the model was created.

Documentation should come from every stage of the model lifecycle, including information on creation and evaluation of the code used in a model, on the decision behind use of an appropriate algorithm or mathematical equations, on how the inputs 
were chosen, and finally from an accounting of all the uncertainties (NAS 2007, 2009).

Such information needs to be clear to the lay public, revealing how decisions about model construction were made. Some of this information obviously requires a level of knowledge concerning models beyond the experience of ordinary citizens (such as complex decisions concerning algorithms).

The AQAUTOX model is an example of a transparent model with good evaluation, validation, and thorough documentation. It makes clear the possible insufficiency of outside information that can be used to fully validate all of the outputs that the model creates (Models Knowledge Base, 2009). This is an important point. The fact that it is openly addressed in the Models Knowledge Base (and elsewhere) helps in avoidance of future legal trouble over lack of transparency or full disclosure of the model's limitations. A review of legal cases on utilizing models in regulatory decision making found that although a model may not be fully validated, if the EPA properly addresses the deficiency, the court tends to rule in favor of the agency. However, if the agency does not properly address inadequacies in the model, often the court rules against the agency on the grounds that they did not properly disclose all information (McGarity and Wagner, 2003).

Consistency. The last important issue that needs to be considered is that of consistency. The models that are being used within the agency need to be subjected to the same set of rules so that there is consistency throughout the agency on the evaluation and use of models (CREM, 2009). However, it is difficult to create policy that is relevant to all models that are created and used, whether inside or outside of the agency. Since every model is different, rules need to be somewhat flexible (Interview \# 4, 2009). 
Generalizing all models into a single category and trying to address the common issues is complicated, and some might say unreasonable. This subject is a source of tension between those that believe that there is a need for general agency guidelines that apply to all models equally, and those that believe that since every type of modeling is different the guidelines should be specific to each case (Interview \# 10, 2009). Even though consistency is difficult to achieve due to the wide range of model types, it is actually due to these differing model types that it is necessary to have consistency.

Despite the problems with uncertainty, transparency, and consistency, scientists at the EPA view models as the most effective way to predict the outcomes from environmental problems and develop regulatory strategies that serve as adequate solutions. Without models, agencies such as the EPA would not be able to keep track of environmental pollutants and would not have the necessary information to create the detailed regulations necessary to protect environmental and human health.

\subsection{Model Use at EPA and Other Federal Agencies}

The EPA is one of many federal agencies that use models in decision making. While most of these agencies are not regulatory agencies, the models that they use for research and planning often end up influencing policy. The Department of Transportation, for example, mainly uses planning models, economic models and emissions models. Looking at climate change issues as an example, DOT uses economic models is to measure and compare the cost and benefits of transportation activities and control measures relating to climate change issues. Emissions models can be used to estimate energy use and criteria pollutant emissions from transportation sources (DOT, 
2009). Another important regulatory agency that uses models in decision making is the Food and Drug Administration (FDA). One example of how FDA uses models is with risk assessment and life cycle models to analyze and approve new pharmaceuticals (FDA, 2009).

The Department of Transportation (the Federal Highway Administration, Federal Transit Administration and the Office of the Secretary of Transportation) and the EPA partner to fund and support the Travel Model Improvement Program (TMIP), which is a program developed to support planning agencies through improving and supporting planning analysis. While part of this program is to further develop models and make sure that they are being used appropriately (DOT, 2009), it does not attempt to create general modeling guidance like the CREM.

The EPA faces challenges since it is not only a regulatory agency that has to develop regulations and follow through with compliance and enforcement, but it is also responsible for conducting original research to help support their regulations and further improve environmental and human health. Because of its far reaching scope of responsibilities, it is reliant on a wide range of model types.

Currently, almost all models used for decision making within the agency are computer models. The National Academy of Science report on regulatory models does a good job of both describing the categories of models that are used within the agency, and how these models have been used in regulatory decision making. The report identifies the following categories of models, all of which are used in some way within the EPA (NAS, 2007): 
- HUMAN ACTIVITY MODELS - "Activity models simulate the human activities and behaviors that result in pollutants.” (i.e. transportation models) (NAS, 2007)

- NATURAL SYSTEMS PROCESS AND EMISSIONS MODELS - "Natural systems process and emissions models simulate the dynamics of ecosystems that directly or indirectly give rise to fluxes of nutrients and other environmental emissions.” (NAS, 2007)

- EMISSIONS MODELS - "These models estimate the rate or the amount of pollutant emissions to water bodies and the atmosphere.” (NAS, 2007)

- FATE AND TRANSPORT MODELS - "Fate and transport models calculate the movement of pollutants in the environment.” (NAS, 2007) Subcategories of fate and transport models include: Subsurface, Surface Water Quality, and Air Quality.

- EXPOSURE MODELS - "The primary objective of exposure models is to estimate the dose of pollutant which humans or animals are exposed to via inhalation, ingestion and/or dermal uptake.” (NAS, 2007)

- HUMAN HEALTH AND ENVIRONMENT RESPONSE MODELS - "Health effects models provide a statistical relationship between a dose of a chemical and an adverse human health effect. Ecological effects models, like human health effects models, define relationships between a level of pollutant exposure and a particular ecological indicator.” (NAS, 2007) Subcategories include: Human Health Effects and Ecological Health Effects.

- ECONOMIC IMPACT MODELS - "This category includes a broad group of models that are used in many different aspects of EPA's activities including: 
rulemaking, priority setting, enforcement, and retrospective analyses. Models that produce a dollar value as output belong in this category.” (NAS, 2007)

- NONECONOMIC IMPACT MODELS - "Noneconomic impact models evaluate the effects of contaminants on a variety of noneconomic parameters, such as on crop yields and buildings.” (NAS, 2007)

These different categories of models are used in a variety of different decisions. The NAS report categorizes the major documents that have relied on computational modeling as follows (NAS, 2007):

- Air Quality

○ Documents related to establishing National Ambient Air Quality Standards (NAAQS)

- Amendments establishing the need for State Implementation Plans (SIPs)

- Regulatory Impact Assessments (RIA) related to air quality rules

- Water

○ Determination of Total Maximum Daily Loads (TMDLs)

○ Leaking Underground Storage Tank Program

- Establishing Maximum Contaminant Level of Drinking Water

- Pesticides and Toxic Substances

○ Pre-Manufacturing Notice Decisions

○ Pesticide Reassessments

- Soil and Hazardous Waste

○ Superfund Site Decisions

- Human Health Risk Assessment

- Benchmark Dose Technical Guidance

- Carcinogen Risk Assessment Guidance

- Ecological Health Risk Assessment 


\section{○ Ecological Risk Assessment Guidance}

This categorization shows how many of the major documents and project of the past few decades have relied heavily on the use of computational models. It also shows the broad range of media that rely on models as well. Since the EPA spans such a large amount of media, they must rely on more types of models than other federal agencies. For example, the FDA would rely more heavily on human health risk assessment models and perhaps exposure models, but would not have much use for atmospheric fate and transport models, where as the EPA uses atmospheric fate and transport models to determine how a contaminant might reach a human, and then must use exposure and risk assessment models to determine how humans are exposed to the contaminant, and what risk that poses to human health. This is one of the main reasons that an entity like the CREM that provides general modeling guidance and also acts as a community facilitator is crucial in an agency like the EPA.

The EPA is obviously not the only federal agency that uses scientific information in decision making and is one of many agencies that rely on models when real world data is not an option. Since many regulatory agencies are structured similarly to the EPA, it is appropriate to say that they most likely face the same challenges with model use as the EPA does and therefore lessons learned from the CREM may be applicable to future efforts to address these challenges.

\subsection{Conclusions}

As environmental problems become more advanced and complex, science plays a more important role in decision making. This creates more challenges in the science 
policy field. Due to the inevitable uncertainty associated with scientific information, the decisions on how, when and to what extent to use science in decision making is increasingly more challenging, especially when dealing with the newer realm of regulatory science that brings a new set of issues. Not only is it necessary to reduce the level of uncertainty as much as possible, but there is pressure to do it as quick as possible since the need for regulation is driven by politicians with little regard for the amount of time necessary to produce sound science. These additional challenges are often more prevalent in the “meso" level since federal agencies are often under a great deal of political pressure and scrutiny from the public. The issues that arise when using models in regulatory decisions parallel the issues faced when using any type of science in a decision. This makes successful implementation of science policy programs to address these issues crucial. The research on implementation strategies shows how difficult it is to find the proper balance to successfully implement science policy. 


\section{Chapter 3: Council for Regulatory Environmental Modeling}

Examining the Council for Regulatory Environmental Modeling (CREM)

provides an informative look into the science policy implementation process with a focus on models, which have become a heavily used source of scientific information in many federal agencies. The CREM was created to address the many modeling issues that were identified throughout the agency. A thorough examination of the history of modeling at the EPA and the events that led to the creation of the CREM will also help shed light on why it was necessary to implement policy on modeling. This history will also allow for parallels to be drawn between previous attempts at modeling policy and the CREM. The history of the CREM itself highlights events that have motivated the actions of the CREM as well as the several impediments to implementation of CREM policies. This discussion includes the origin and goals of the CREM, its major projects (the Models Knowledge Base and the Guidance Document), and the CREM's current activities.

\subsection{History of Modeling Policy at the EPA}

Models have been used in regulatory decision making since the EPA began its work in 1970. However, the extent of model use has varied throughout the years. Computer models were obviously not as complex as they are today when the Clean Air Act or the Clean Water Act were developed (NAS, 2007). The simple models that existed at the time were so basic that they had little to no affect on regulations (NAS 2007). Generally, they were extrapolation models used in risk assessment that presented a high level of uncertainty and were subject to very little evaluation (EPA, 1987). Today, models are much more complex and are used to address regulations in almost any area 
dealing with the environment. One common example is the use of models to estimate the fate and transport of chemicals or pollutants to demonstrate how a specific chemical might travel within the environment. This is useful, for instance, in determination of chemical contamination of a water supply, and its effects on human and environmental health. As models became more complex and refined, they started to play a larger role in regulatory activities, thus introducing public concern with how they are used in controversial decisions. In response, the EPA has had to develop a coherent policy addressing use of models throughout the agency.

Over the past three decades, the EPA's Science Advisory Board (SAB) has provided recommendations for model use within the agency. In the beginning, the advice consisted of looking at each model separately. It was common for recommendations to be similar in every model review. However, the SAB remained reluctant to review models as a whole set with many generic recommendations in common. There was some pressure to develop model policies to cover whole groups, especially extrapolation modeling and evaluation of chemical substances. Yet, the pressure was not adequate to advance a comprehensive modeling policy. Instead, the thrust of the agency at this time was primarily on the problem of integrating modeling into decision making (Interview \# 12, 2009). It was more important to focus on the use of science in policy, rather than on policy about the science itself.

This mindset began to change in the mid-1980s. It was apparent that the SAB was making the same recommendations over and over again, yet the message was not absorbed by the agency. Even within individual program offices, it seemed as though the recommendations that were made for one model were not carried over into future models, 
even though the same situations that required model use were repeated (Interview \# 12, 2009). It became obvious that if a comprehensive policy for model use was established for the entire agency, a significant amount of time and resources could be saved.

As a result, the Chairman of the Executive Committee of the EPA's SAB initiated a discussion on model validation in a letter to the EPA Administrator in 1984, recommending that "systematic effort of model validation be initiated, including identification of the appropriate balance between monitoring and modeling” (SAB, 1984). This marked the first time that models were addressed as a subject requiring an agency policy. However, in spite of this initiative, the EPA continued during the 1980s to focus on particular model types (i.e. extrapolation, fate and transport, etc), as it had in the past. The proposal for a policy on modeling was ignored.

In an effort to raise the issue again, the SAB released a report in 1989 suggesting that the agency develop guidelines on the validation of models (including model evaluation) and that a task force be formed to oversee and guide the use of models within the agency (SAB 1989). This time, the agency acted. In response, the EPA developed the Agency Task Force for Environmental Regulatory Modeling (ATFERM) in 1992. The main product of the ATFERM was a 1994 document that evaluated the strengths and weaknesses of agency modeling, concluding that there was little consistency within the EPA on how models were evaluated, and advocated for a uniform model evaluation process to be implemented throughout the EPA (AFTERM, 1994). However, these suggestions were never fully implemented. It was apparent that fixing the modeling issues within the EPA would require an institutional change that would necessitate a great deal of attention throughout the agency and take many years to fully implement 
(Interview \# 12, 2009). It is not possible to have institutional change of this magnitude without top down support.

\subsection{Origins of the CREM}

After the ATFERM report, the members of the Taskforce were not willing to give up on what they believed to be a very important issue. They decided to hold the Models 2000 Conference in December, 1997 to reinvigorate the idea of a policy on modeling. The conference had a larger than expected turnout, with almost 100 people from throughout the Agency attending (Interview \# 6, 2009). The result was a proposal to establish the Council for Regulatory Modeling (CREM). It was followed in 1999, by the EPA’s SAB approval of the 1997 proposal (SAB, 1999) which provided the administrative mechanism to properly implement the CREM. The advisory board decided that the CREM would guide the creation and use of models throughout the EPA and be responsible for communications with the public on agency use of models. The board did express doubts, however, as to whether the agency was fully committed to development of a policy on modeling. It noted that the ATFERM had not been properly supported, and therefore was not very successful. The EPA needed to be prepared to fully support the CREM, or the CREM too would not reach its full potential (SAB, 1999).

Three years after the proposal, the "Framework for the Council for Regulatory Environmental Modeling” was released in an administrative memorandum. Officially established, the CREM was "to promote consistency and consensus within the Agency on mathematical modeling issues” (EPA, 2000). The Framework detailed the CREM's scope of activity and membership structure. The scope of activity focused primarily on 
strategic planning to provide guidance to model creators throughout the agency on model evaluation, verification and validation (EPA, 2000). The membership structure, in addition to the few staff members that would work specifically for CREM, included representatives from all offices within the agency. These representatives would form two groups in the CREM, the Council and the Workgroup. The Council would consist of higher level employees (mostly management) from every program office and would act as more of an oversight body that provides feedback and approval for proposed projects, while the Workgroup would consist of model creators and users that are not in higher level positions that would act as more of the action group that works on the individual tasks and projects of the CREM.

The CREM faced some initial struggles. The most important had to do with where CREM would reside and be funded within the organization. The current Assistant Administrator of the Office of Research and Development (ORD) agreed to house the CREM in the ORD office for the first year if another office would agree to house them for the second year. However, no one came forward with the $\$ 50,000$ that was necessary to fund the CREM (Interview \# 12, 2009). A second issue came from outside the agency. The year 2000 was an election year. Agency staff were uncomfortable with establishment of a new office that might be eliminated with an administration change (Interview \# 12, 2009). Interestingly, the change in the White House ended up being the solution to both of these problems. A new Administrator, Christine Todd Whitman arrived at the Agency with the "declared" mission to promote sound science (Interview \# 12, 2009). She appointed Paul Gilman as the Assistant Administrator for ORD who supported establishment of the CREM, decided to house it in ORD indefinitely, and 
brought the new initiative to Administrator Whitman's attention. Whitman then released a formal public statement on science policy -- "Strengthening Science at the Environmental Protection Agency” -- and named Paul Gilman EPA’s Science Advisor. One of eight responsibilities that Whitman designated for Gilman was the revitalization of the CREM (EPA, 2002). Thus, by 2003, the CREM then had both a strengthened membership base and strong support from the Administrator.

Two important factors that emphasize the importance of the CREM's work are the legal challenges faced by the agency in regards to the use of certain models in regulatory decision making and the Data Quality Act

Legal Challenges and the Administrative Procedure Act. There are many legal issues that must be considered and accounted for when using models in regulatory decision making. People negatively affected by one of EPA's regulations can choose to challenge the regulation on the basis of the model used.

In order for a person or group to challenge a regulatory decision, they must challenge the constitutionality of the decision, or the challenge must be based on legislation that authorizes the court to review decisions based on certain criteria. In the case of regulatory models, that legislation is usually the Administrative Procedure Act (McGarity and Wagner, 2004). The Administrative Procedure Act dictates the process that agencies use to propose and create regulations and also designate the process for judicial review by the courts (Administrative Procedure Act, 1946). More specifically it gives the court the power to ensure that "the agency is following requirements set in the authorizing statute; is not promulgating rules that violate or fall outside the bounds of the authority delegated the agency by statute; is following prescribed process for 
promulgating rules, such as notice and comment; and is not promulgating rules that are arbitrary in relationship to the facts” (McGarity and Wagner, 2004).

One of the ways that someone can challenge a regulation is by challenging the rulemaking process used by the agency. The APA requires that the public have the opportunity to comment on the proposed rule, and that it provide it sufficient information to do so. In terms of modeling this means that the EPA must inform the public that it intends to use a certain model and provide enough information about the models that the public can comment on the assumptions and algorithms (McGarity and Wganer, 2004). In order to avoid reversal of a rule due to insufficient attention to notice and comment the EPA should be sure to provide a detailed description of the model, identify the assumptions of the model, explain the validity of the assumptions in the context of the particular application and request comments about the assumptions (McGarity and Wagner, 2004).

The other main legal challenge that models face it the substantive review process in which the rule is subject to two tests. The "substantial evidence" tests requires the court to examine the evidence used to ensure that it is adequate to support the conclusion and the "arbitrary and capricious" test which determines whether the agency relied on the factors that Congress intended, considered all important aspects of the problem, offered proper explanations and whether the decisions is plausible (McGarity and Wagner, 2004). Under this review process, there are many aspects of the model that can be challenged. Some of the ones presented in the review conducted by McGarity and Wagner (2004) are:

1. Challenges to the assumptions embedded in the models - including oversimplification of the general model used by the agency, failure to adjust a 
generic model to make it more applicable to a particular circumstance and working with inappropriate assumptions.

2. Challenges to data and statistics used in a model - including challenges to the input data or studies (i.e. unrepresentative data or outdated studies) and challenges to the statistical decisions.

3. Validation and peer review of EPA's models

4. Agency's placement of its models within the larger context - Including departure from prior models, arbitrarily choosing a model when better alternatives exist, and inadequate explanation of final results.

While this list of possible ways that a decision can be challenged due to model use seems quite daunting, the courts have been understanding of the fact that models are imperfect representations of reality and therefore does often give the agency the benefit of the doubt as long as it is obvious that they did everything in their power to follow the appropriate process of providing information and explaining their assumptions and choices in a comprehensive manner (McGarity and Wagner, 2004).

Data Quality Act. The Data Quality Act was passed by Congress in 2001, and required the Office of Management and Budget (OMB) to develop guidelines ensuring the quality of disseminated information to all federal agencies (Section 515 of the Treasury and General Government Appropriations Act, 2001). The Act required that all federal agencies develop their own management guidelines and procedures in compliance of OMB. Since models fall under the jurisdiction of this Act, there was a push for the CREM to respond quickly. The EPA's quality guidelines stated the models should be useful, objective, transparent, and reproducible and that models used for risk assessment 
should rely on the best available practicable science. Looking at these guidelines, it is apparent that many of the goals and activities of the CREM are focused on meeting these guidelines, although the Data Quality Act may not always be referred to as the reason behind the goals and activities. One other important thing that was motivated by the Data Quality Act was the realization that the CREM needed to not only focus on model developers, but also model users. Model users are usually the agency decision-makers that apply the models to regulatory decisions. They are interested in accurate and comprehensive information about individual models. While the Data Quality Act has been a major factor in launching the work of the CREM, it is predicted that it will not be a cause for legal challenges in the future (McGarity and Wagner, 2004).

Aside from the major legislation that affected models, a few administrative memos in 2002 and 2003 were very important in initiating CREM activities. Christine Todd Whitman released two very important memos in 2002 and 2003. The first focused on staffing the CREM and increasing its membership. This resulted in the acquisition of a full time staff member for the program. Until that point, staff support for development of an agency-wide modeling policy consisted of members of ORD who were only dedicated part time to the Council. Gerardo "Pasky" Pascual was named as the Team Leader for the CREM in May 2002 (EPA, 2002). Further, each Science Policy Council member designated a senior manager from their office to serve as a member of the Council, thus creating a more representative structure. These designations strengthened the Council and helped build some of the connections that make up the organizations of the CREM (see appendix C). 
In February 2003, Whitman continued her focus on strengthening science and issued a memo that specifically addressed the work of the CREM, requested continued support of the Council for Regulatory Environmental Management from all agency offices, and listed her expected accomplishments for the CREM for 2003 (EPA, 2003). The memo specifically mentioned the newly effective Information Quality Guidelines (EPA's response to the Data Quality Act) as an impetus driving the CREM to further address modeling issues (EPA, 2003). These guidelines made the agencies use of models visible to the public and stakeholders (EPA, 2003). With these actions, the CREM officially became the mechanism for implementation of a policy throughout EPA that coordinated development and use of environmental models for regulatory decisions.

The year 2003 was dedicated to meeting the expectations that Whitman laid out in her memo. As one of its first actions, CREM developed an inventory of EPA models, known as Models Knowledge Base (MKB). This a public database of models used within the EPA, whose purpose is to provide easy access to basic information about the models, including how they are used, their scientific basis, and the extent they are evaluated. During the next several years, the CREM also collaborated with the National Academy of Sciences (NAS) in a project to develop recommendations for best practices in using environmental models. In addition, during this same period, it began to draft a guidance document on model development, evaluation, and application (EPA, 2003). Its purpose was to guide agency staff in sound evaluation of models. These developments, discussed in more detail below, illustrate important themes concerning the implementation of science policy (the CREM agenda) in a regulatory agency (EPA). 


\subsection{Models Knowledge Base}

The Models Knowledge Base, one of the first initiatives of the Council, was created to be a central location for information about models utilized throughout EPA (CREM, 2007). It is designed to provide all of the basic information that can assist staff in identification of an appropriate model for specific regulations, and to direct them toward additional information. The early discussion of the knowledge base included a debate over whether or not the general public was an appropriate audience (CREM meeting minutes, 2/1/03). The decision was finally made to make the knowledge base available to the public. The primary reason was the argument that when there is an EPA publication citing use of a particular model, the information about the model needs to be available to a public that would conceivably play a role in discussion/comment over pending regulations (CREM meeting minutes, 2/1/03).

There are three parts to the knowledge base, General Information, User Information and Model Science.

The section "general information" provides an overview of the model, contact information for those who use the model, and a link to its home page. The overview of the model is intended to give a short description of what the model does and what it is used for as well as any substantive changes that have recently occurred and any plans for further model development. The main purpose of this first page is to provide basic information about the model and direct the user to websites and people that can provide them with further information.

The section on user information includes the technical requirements to run the model, a link to the user's guide, the necessary inputs, the basic outputs and any other 
information necessary for someone to be able to use the model. It allows the user to determine whether or not they have the expertise to use the model, and provides information on any resources available to help the user.

The section on model science presents the conceptual basis of the model, the science behind the model, the model framework (equations and algorithms), and information about the model evaluation. This section is more technical in nature, allowing the user to understand the algorithms and equations that are used in the model and why they were chosen.

The Council regularly attempts to update the Models Knowledge Base, often adding new models. The information about the individual models is provided by the model developer, or someone in the agency that is in charge of agency use of the model (if it is a proprietary model). In total, the knowledge base is a reference tool for EPA staff and the public to understand (and use) models that are applied within the agency to regulatory decisions.

\subsection{NAS Report}

In 2002, the current Science Advisor Paul Gilman told the Council that he not only wanted the CREM to emerge as a leader in environmental model development within the EPA , but also as a leader outside of the agency (CREM Meeting Minutes, 9/17/02). It was this vision that prompted Whitman's expectations of the CREM to include collaboration with the National Academy of Sciences to "develop a report recommending best principles and practices in using environmental and human health models for decision-making” and to "establish a stakeholder group of environmental 
model users outside the EPA to interact with CREM and the National Academy of Sciences for the benefit of the broader community of model users” (EPA, 2003). The CREM spent approximately $\$ 1$ million dollars on the NAS report whose purpose was to discuss regulatory modeling use that would reach a broader audience (not just those within the agency) (Interview \# 6, 2009). Modeled on an earlier NAS report on risk assessment, the hope was that the Academy would provide a "redbook" on environmental modeling that could be widely used and cited (Interview \# 6, 2009). The goal was to help create modeling consistency throughout the wider community outside of the EPA. The original charge to the expert panel requested that it address specific issues:

1. identify the scientific factors that should be considered in developing model-acceptability and application;

2. determine how the EPA can create guidance that is applicable across the agency;

3. determine how to address issues in a unified manner;

4. determine how proprietary models can meet the acceptability and application criteria;

5. determine if there are unique evaluation issues within unique categories of models;

6. determine how models can be improved in an adaptive management process allowing for models to be simpler and more flexible;

7. determine how uncertainties and limitations can be communicated effectively and how secondary model uses should be handled; 
8. and identify the advances that may affect the selection and use of models such as emerging sources of data and developing information technology (EPA, 2003).

The NAS put together a group of experts, primarily from academia, to form a workgroup and address the charge and, after about two years of work, the workgroup produced a report that focused on a definition of model evaluation, its role in regulatory science, and recommendations for model improvement at the EPA. On model evaluation, the report notes that because of the complexity of models, model evaluation is not simply a comparison of model results to actual measurement data (NAS, 2007). Evaluating regulatory models is different from evaluating research models. Regulatory models not only need to be accurate, but also must be transparent, reproducible and applicable to a particular regulation (NAS, 2007). The NAS also offered up an extensive list of recommendations regarding model evaluation, the most important stating that model evaluation should occur continuously throughout the model life cycle (development, application, revision, regulatory use, etc). Each model, therefore, should have a life cycle evaluation plan (NAS, 2007).

The report also points out that there has been insufficient effort by the agency to learn from prior experiences to determine if systematic improvements can be made in the future for specific models or classes of models (NAS, 2007). The two main areas that were identified where this could be done are with classes of models and individual models. Examining classes of models, such as groundwater models, could help determine if there are strengths and weaknesses that are characteristic of certain model 
types (NAS, 2007). The other approach is examining individual models, in particular models that are considered old by current standards. These older models would provide an opportunity to "asses actual model performance quantitatively by using subsequent advances in modeling and in new observations” (NAS, 2007).

Interestingly, in retrospect, there is little difference between the completed NAS study of 2007 and the guidance document produced by the CREM staff which was prepared during the same time period. Both of the documents addressed regulatory modeling within the EPA, and both offered recommendations for best practices for regulatory modeling. However, this was not necessarily the intended outcome. The CREM had hoped that the NAS report would reach a larger audience, he Academy panel (workgroup), however produced a report that primarily reviewed EPA's modeling practices and provided recommendations for EPA staff (which is more the goal of the guidance document) (Interview \# 6, 2009).

Although the document did not accomplish exactly what the CREM had hoped, it did offer original thought and perspectives - such as the recommendation on continuous evaluation of regulatory models using the life-cycle method and using retrospective analysis to develop systematic improvements for the future - that have proved helpful to the CREM in fulfilling its goals and creating the guidance document. The CREM is currently working on developing an agency-wide workshop to respond to the recommendations made in the report and determine how best to implement them into agency practices. 


\subsection{Guidance Document}

After the burst of activity in 2003, the Council embarked on few new activities. The staff of three focused primarily on completion of the guidance document, which is currently being finalized, and entitled "Development, Evaluation and Application of Environmental Models”. At that point the Council asked the Science Advisory Board to evaluate the draft document on whether it had sufficiently and appropriately identified best practices for model use, described their goals and methods, proposed a graded approach to addressing the issues and supplied practical advice for decision makers who use models (EPA, 2005). The Council also requested recommendations for improvements (EPA, 2005). After its review of the guidance document, the SAB recommended that it be written so that it is more comprehensible to all audiences, use model terminology more consistently, and provide additional technical recommendations such as appropriate evaluation techniques. Generally, however, the SAB was pleased with the draft guidance document (SAB, 2006). The support of the SAB was an accomplishment for the CREM. The Guidance Document was at the time, and still is, seen as their largest project. In terms of science policy, it is the only EPA project that addresses modeling issues and suggests solutions. Since the SAB is made up of experts in various fields of science, this was validation not only of the guidance document but of the CREM itself.

The guidance document is broken up into three different categories: model development, model evaluation, and model application. Model development is focused on four main steps: identifying the environmental problem that needs to be addressed, building a conceptual model, creating the mathematical framework, and parameterization 
(CREM, 2008). Model evaluation is a process that determines whether a model and its results are of high quality, and if evaluation is applied throughout the lifecycle of the model (CREM, 2008). Model application is based on transparency and is strengthened with complete documentation and communication between model creators and decision makers (CREM, 2008).

The document specifies how models should be classified by "type” of model (air quality, economic, etc.). It also identifies three different categories of regulatory models: models used for policy analysis, models used for national regulatory decision making, and models used for implementation applications (CREM, 2008). Models used for policy analysis affect large scale policies that can include multi-year projects and programs (CREM, 2008). Models used for national regulatory decision making are used in decision after a large scale policy is set (CREM, 2008). For example, if a large scale air quality policy is already created, a model may be used to regulate a particular pollutant, such as $\mathrm{SO}_{2}$. Models used for implementation applications are usually used on local scales or for court ordered reasons (CREM, 2008).

Regardless of individual views on whether or not the guidance document will be useful to the modeling community, it does, on the basis of content, achieve one of the main goals of the CREM, to provide guidance on the best practices in model evaluation and use. It also successfully addresses the main issues of transparency, consistency and uncertainty. The Data Quality Act has had an important effect upon the EPA's method of communicating with the public. With modeling, this poses a significant challenge since models tend to be "black boxes". If you do not understand how a model works, then you just see inputs go in and outputs come out, and are oblivious to what goes on in between. 
The guidance document addresses this issue by making sure that every step in the model lifecycle is addressed and by discussing best practices for communication about models.

The process by which the guidance document finally came together over six years illustrates several types of difficulties in the implementation of science policy in a regulatory agency such as the EPA. In the beginning, with the lack of adequate agency staff, it proved difficult for the Council to get volunteers to help with the document. The workgroup members had their own jobs and responsibilities within their regions and programs, and most were not willing to sacrifice the integrity of that work to spend the time authoring the document (Interview \# 4, 2009). This left a large majority of the work to the CREM staff. The CREM had to focus their efforts not only on producing the document, but on finding individuals to participate and offer expertise, which probably contributed to the length of the process.

Interviews with agency staff reveal that the CREM consulted with numerous modeling groups throughout the agency in order to gather information for the guidance document. Specifically, they consulted with groups that were considered more established in model evaluation, already following the protocol that the CREM eventually included in the document. This led to some hard feelings, because, as one interviewee noted: "CREM is taking a lot of credit for things that other people have done" (Interview \# 10, 2009).

Since the CREM has invested so much of its time and resources into this document, it is important to reflect on how people view the document. There was a consensus in the interviews for this study, with a few exceptions, that the guidance document is successful at addressing the general issues. However there were a variety of 
views about what the document will actually accomplish and what it means for people involved with modeling throughout the agency. Some believe that the document will never be successfully implemented. Others believe that since it has taken so long to finish the document it is no longer relevant. Since the guidance document is one of the most important products of the EPA's science policy on modeling, these perceptions are crucial to understanding some of the problems with implementing science policy.

According to the information gathered from the interviews, views on the utility of the guidance document are split. Some see the recommendations and guidance provided within the document as things that are already accomplished, and therefore not very useful to the modeling community. "I would say that it is lagging for us because we have already gone through the steps, we have jumped through all of the hoops so it doesn't really affect us at all” (Interview \# 9, 2009). This seems to be the view of individuals who are from modeling groups that already comply with the guidance document, and who might benefit more from more up to date policy that addresses the next generation of modeling issues that they are currently dealing with. However, other interviewees mainly individuals from regional offices or not part of large modeling groups that could benefit from the guidance - believe the document to be a strong document that appropriately addresses the issues that are faced within the modeling community. They feel as though, if nothing else, the document shows that much needed progress is being made towards addressing issues, which has taken decades to accomplish. "It's been pulled together in an excellent way and it's useful to the agency. I think the CREM has done an admirable job. I think it's a good reference point to move forward on” 
(Interview \# 10, 2009). These differences of opinion can sometimes act as an impediment to implementation, as is later discussed.

\subsection{Conclusions}

The Council has developed multiple projects since it began in 2000 to address many of the issues with modeling at the EPA. The products of these initiatives comprise the basic structure of the EPA's science policy pertaining to environmental regulatory modeling. The NAS report in tandem with the guidance document lay out processes to make sure that models used in regulatory decision making are of the highest quality. They look at the model as a lifecycle, identifying the steps that need to be taken at each stage of the cycle, and establishing the documentation and communication requirements necessary for a legitimate and appropriate model for regulatory decisions. The Models Knowledge Base serves as a clearinghouse, providing a central location for basic information about the models used throughout the agency. Although it has not yet included all environmental models utilized at the EPA, it is the most comprehensive bank of model information that can currently be found.

Today the Council is focused on three activities: completion of the revised guidance document, responding to the NAS 2007 report recommendations, and providing workshops on integrated modeling for EPA staff. The guidance document went out for a 30 day public comment on August 13, 3008, and the final draft is in process. 


\section{Chapter 4: Impediments to Implementation}

\subsection{Introduction}

The main findings from my observations, interviews and document review revolve around some key themes, many of which draw parallels to the common problems faced in dealing with science policy implementation. The most significant finding from the interviews conducted for this project is the wide range of impediments to implementation of the EPA's modeling policy. Generally, the impediments to policy implementation fall into two groups, classic and paradoxical. The first group includes the more standard impediments to science policy implementation that might be found in any regulatory environment. These are impediments that are clear in cause and solution. For example, if a lack of resources is one of the impediments that the CREM faces, then it is obvious that better financial support from the agency could help to eliminate the problem. There is a clear roadblock that needs to be moved in order to have a greater level of success in the implementation process.

The second category is more paradoxical in nature. Specifically, the solution to the impediment creates another problem and a cyclical effect that tends to be irresolvable. For example, the CREM faces the challenge of implementing guidance without being the "model police”. Without authority, it is difficult to implement. However, playing a policing role could elicit hostility from the modeling community. In effect, the cyclical effect does not enable identification of a clear roadblock that can be removed. For example, one of the goals of the CREM is to implement the guidance document. However, the CREM also does not want to take on the role of the "model police". Without the police role it is difficult to get people to comply, but once the CREM is seen 
as the "model police" people will have a different view of the CREM, which might result in a lack of support from the modeling community.

\subsection{Classic Impediments}

The first group of obstacles to policy implementation includes classic examples of impediments. I have identified four major examples: resources, organizational structure, breadth of modeling categories, and politics.

\section{Resources}

Throughout the interviews, the most common response to the question "What have been CREM's impediments to success?” was a lack of resources. "It's obvious that a lack of resources impedes the CREM's successes, because in order to go scale up you need a certain amount of resources to build the ontology, the foundation” (Interview \# 12, 2009). At the most basic level, it is essential for a program to have sufficient resources as a foundation to build upon. This interview brings up the point that the CREM has had a lack of resources from the very beginning. It was never able to establish itself fully since it never had the necessary resources to do so.

This lack of resources has continued throughout the life of the CREM. Currently, the CREM only has one staff member to organize the day to day activities as well as plan for future projects. Since one staff member cannot possibly accomplish all of the necessary tasks, it is necessary to turn toward the workgroup for help. "The CREM is just not resourced - one person trying to run quality throughout the entire agency is just not going to work” (Interview \# 20, 2009). 


\section{Organizational Structure}

The CREM is organized in such a way that it is reliant on participation from nonstaff members in order to be successful. Currently, the CREM only has one staff member and cannot achieve its goals without the support of the council and the workgroup. The council is made up of higher level members of the agency, such as office managers and branch chiefs that have the power to make changes that will affect their entire office. The workgroup is made up of one (in some cases two) employees from each office or region who are not in management positions, but who do work directly with models. The workgroup members act as the liaison between their office and the CREM. Some of these workgroup members volunteered themselves for this position and others were appointed by management.

The organizational structure of the CREM is effective in theory. The workgroup attends more CREM meetings than the council and provides input and feedback. Some members volunteered their time to help with CREM projects, such as authoring the guidance document. The council, composed of higher level staff (i.e., branch chiefs), has the power to take the CREM's guidance and implement in their own programs. However, according to my interviewees, the council rarely played the role intended by the EPA policy that created it. The council members rarely attend the few meetings a year required, and many of them were unaware of many of the activities of the CREM. A number of respondents noted that this was due not to a lack of interest, but rather to the busy schedules making it difficult for attendance at meetings. One interview noted about the CREM: 
"It seems to me they lack authority. And I know that they have the Council, but I don't know that their people ever actually go to these meetings because they are extremely busy people and don't have time to deal with it. So, I don't know how well manned or representative the Council actually is. You would have to have buy in from people at that level of management in order for anything to have teeth - otherwise it's just these recommendations that these people may never read. However, if it comes from your boss and they say that this is how we are going to do things, then you will pay attention” (Interview \# 17, 2009).

For example, if a model creator has certain protocols that he/she is required to follow as set forth by the program director, then the policy is followed, or implemented. Without the prompt from a supervisor, a model creator may not independently implement the guidance given by the CREM for fear that he/she will not have the adequate time and resources to do so. However, if the Council members were more active with the CREM in implementation of modeling policy, the modeling community would be actively utilizing CREM's guidance and the success of this science policy might be perceived more favorably.

Although the Workgroup participates more in CREM activities, its meetings are also often lacking in attendance. In my experience at the agency, the Workgroup meetings were sparsely attended. More often than not, when prompted to volunteer to help plan a workshop or author a white paper for the guidance document, few, if any, people stepped forward. In practice, most Workgroup members do not have the extra time to dedicate to the CREM.

"There is recognition that this is important and you should keep an eye on it, but most don't have a lot of time to give to help. Another issue is that for each 
office, there is only one representative and they are supposed to communicate with their office and they don't have the time to do it unless the office's name and reputation are on the line” (Interview \# 21, 2009).

Since the CREM has only one staff member, and the Council and Workgroup are often hesitant to participate, the CREM must sometime seek outside help from the modeling community in order to achieve their goals. Several people interviewed point to this lack of support and staff as one of the primary impediments that the CREM faces.

Another organizational issue that the CREM faces is not with how the CREM is organized, per se, but with how the agency is organized as a whole. EPA headquarters in Washington, D.C. is separated into program offices based on different environmental media (water, air, etc), plus a few non-media departments such as compliance, research and development, etc. There are also ten regional offices through the U.S that have a similar structure to the headquarters, although on a smaller scale. This organizational structure poses a problem for a group that is trying to implement science policy throughout the agency, especially the division between headquarters and the regions. One staff member notes: "I think that since we are all doing different things, it is a challenge for CREM to come up with stuff that benefits everyone. In the regions, we aren’t doing research, we work on very specific projects” (Interview \# 4, 2009) It became clear from the interviews that only a small handful of people work with models in the regions, and only intermittently. In the program offices, on the other hand, there exist modeling groups that are made up of individuals working with some form of modeling all of the time. The individuals in the program offices, therefore, have a better support system then those in the regional offices. This means that there will be different needs 
within the two groups, with the regional offices needing more support and training from a group like the CREM and the program offices not needing as much support, but perhaps benefitting more from the facilitation aspect of the CREM.

\section{Breadth of Interest}

The diversity of modeling programs within the agency is another major impediment to implementing sound modeling policy. "When you start talking about modeling at the EPA, you are automatically in apples and oranges and there is a lot under that umbrella” (Interview \# 4, 2009). Models span a broad range of different media, as well as a broad range of different purposes. The variety of media across which environmental policy works poses a large issue. Those that are dealing with water modeling are facing different challenges than those dealing with air modeling, and their missions or the work that they do is going to be very different. This makes CREM's job difficult as is only one staff member, and that one person cannot possibly be an expert on every type of modeling for every situation within a given media. Ultimately, many people believe that having experts in certain fields of modeling in the CREM could be more beneficial at addressing this issue. "Maybe if the CREM organizes along program lines - you have staff assigned to different media and then you might have more connection between them” (Interview \# 4, 2009)

\section{Administrative Change}

The earliest impediment that CREM has faced throughout its lifespan is the administrative change that comes with each presidential election cycle. "2000 was an 
election year, which always brings about uncertainties. Since the CREM was a new organization and didn’t really have any momentum, people questioned whether it would survive the transition and that made it difficult for the senior management to buy in" (Interview \# 6, 2009). Since administrative change creates a lot of uncertainty at the top levels of the agency, staff members were reluctant to dedicate their time to a policy initiative that might not survive the current Administrator. The CREM recently faced this dilemma with the 2008 election when they tried to hold a workshop to implement some of the recommendations from the NAS report. "We tried to get a workshop going before the election, and we failed to get enough people to want to come. We decided to assume that after the new administration comes in there will be a better turnout” (Interview \# 6, 2009). If the CREM has to deal with this issue every time there is a change in political appointments to the EPA administration, progress on implementation of new projects and programs slows.

\subsection{Implementation Paradoxes}

The types of impediments to policy implementation just discussed are examples of generic problems that potentially face all federal regulatory agencies such as the EPA. However, the CREM also confronts several obstacles that are paradoxes-irresolvable dilemmas that pertain to modeling issues. These issues have no obvious, solution. With the impediments discussed above, there are logical solutions, which, while they may not be possible, are easily identifiable. The paradoxical impediments, however, have no clear solution. The solution of one aspect of a problem may create new problems, or, in some instances, create a cyclical cascade of policy problems. This makes these challenges far 
more difficult to address than normal impediments with clear solutions. To be more specific, there are three major implementation paradoxes evident in the EPA's effort to implement modeling guidance through the CREM: the dilemma of top down versus bottom up initiatives, the effort to implement guidance for staff use of models within the agency without assuming the role of policing, and the resolution of conflicting perceptions of the CREM by EPA staff. In all three instances, there are conflicting goals inherent in the implementation of modeling policy.

\section{Top Down Versus Bottom Up}

One of the greatest challenges CREM confronts is the balancing of top down and bottom up (or grassroots) approaches in its work. In order for the CREM to be successful, it must achieve a balance between a top down and bottom up approach to implementation of models at the agency.

Most of the recent projects undertaken by the CREM came from the Workgroup. A good example is the CREM's work with integrated modeling (the workshops and the white paper). "The integrated modeling activities are purely on the staff level with folks that are interested and passionate and have the experience. However, you still need to get senior management support and endorsement. You need to have the buy in to get the resources” (Interview \# 11, 2009). Typically, the CREM works at the grass roots level, as evidenced in the writing of the guidance document and the building of the Models Knowledge Base. Once a product is completed, the CREM utilizes its resources to gain the support of the EPA Administrator. Then, after issuance of a directive or memo from the Administrator's office, the CREM can push implementation of policy. This 
endorsement by a higher level is imperative, since otherwise the CREM would have a much more difficult time in getting the different regions and program offices to adopt modeling policies. "There was a confluence of events that made things work the way it did - on the one hand you had someone from the bottom that had the ideas and the energy to push, but you also had someone at the top that was receptive and understood what he needed to do” (Interview \# 2, 2009).

The CREM must not only figure out the important modeling issues that need to be addressed, but it must also convince the higher level management that these issues are something that they should dedicate resources to. Sometimes, as was the case with the guidance document and the Models Knowledge Base, this works out well. However, this is not necessarily typical. The CREM also seeks to play the role of facilitator and to create a community of practice for modeling. These projects are often overshadowed by the projects that the people at the top find more beneficial. Guidance documents are big ticket items that draw attention and therefore are more apt to be resourced. Since it is impossible to know what the top administration will find important, it is impossible to find a solution to this problem as a whole. As CREM finds itself unable to predict the level of support from the current administration, it has difficulty employing different strategies to implement effective policies for model use at the EPA.

Another aspect of the top down vs bottom up paradox is the role played by what is termed “political will”. In order for the CREM to accomplish its goals, there has to be the political will to implement them, in spite of fears from senior administrators that implementation of policies might generate a negative effect. "Bureaucrats are very risk adverse and are not going to go in a direction unless they get some clear signal from 
above that this is where they should be going” (Interview \# 2, 2009). This often led to the CREM's lack of resources. If the administration does not think that something is important enough at a certain point in time, the CREM is not likely to get the proper funding and attention that it needs to be successful. This also encourages the CREM to focus its attention primarily upon things that will draw in the most resources. "There is always a political context. CREM has done a good job at pulling things together, some people didn't like integrated modeling in the beginning but do now - it was a political thing because they were trying to draw in resources” (Interview \#10, 2009).

\section{Implementation without Policing}

Another paradox that the CREM faces is the issue of implementation of the guidance without assuming a role as the "model police". CREM determined very early that it would not serve as a policing entity that enforced rules for model use (meeting minutes, 2002). It seemed to the Council that if it assumed this role, it would draw hostility to its policies rather than the cooperation. Since the CREM has such limited resources, they needed people to work with them, and this hostility would have prevented the CREM from accomplishing much of anything.

Without playing a policing role, the CREM faces the challenge of how to get the modeling community to follow the guidance that they are putting out. Guidance without implementation serves little purpose. This plays into the need for top down endorsement as well. As noted previously, the model users in the program offices will follow policy only if their managers direct them to do so. This type of directive would most likely have to come from the level of the administrator, or at least an assistant administrator, in order 
for the managers to pay attention to it. If the CREM had the ability to enforce the implementation of its policies, it would, of course, be successful. However, if they are forcing people to change how they are doing things, the hostility will set in and people will be reluctant to help the CREM and provide input for the guidance, without which the CREM would accomplish nothing. "There is always the fear on the part of the people within the agency that what the CREM is doing will lead to the model police and that it will complicate the lives of the people who are trying to get regulations out the door on a tight timetable or with a court order mandate” (Interview \# 6, 2009).

\section{Differing Perceptions of the CREM}

Overall, from the interviews, there seems to be no clear cut consensus on how the CREM is viewed within the agency. Interviewees articulated positions on the one hand that indicated a broad range of knowledge about the CREM, to positions revealing they knew almost nothing at all. One person that I interviewed stated, "I do not have much experience with the CREM, I don’t really even know what they do” (Interview \# 1, 2009). Another said, “I’ve heard of the CREM, but mostly I have just heard that so and so is at a CREM meeting and that is it” (Interview \# 5, 2009). These two interviewee model creators were obviously not members of the Council itself, but their remarks show that the CREM has not necessarily been successful in reaching the entire modeling community. There is unevenness among individuals in the modeling community as to their level of knowledge of the CREM.

"We were responsible for managing our own models for years and the first time I heard about the CREM was when (at least five years ago) they started asking 
us about our practices with model evaluation....and then suddenly there was this document handed down that was about the best way to handle models, so I do not have the best view of the CREM” (Interview \# 8, 2009).

Because of the lack of knowledge, it was difficult to get a clear picture of whether or not the CREM was beneficial to the modeling community. In order for policy to be effective, everyone involved in modeling in the agency should have at least a basic level of understanding about who the CREM is and what they do. Interestingly, among the individuals who had a limited or no knowledge of CREM and its policies (for instance, the guidance document), there seemed to be a positive impression of the need for a facilitator such as the CREM that would bring the modeling community together to address common problems and discuss their work. These individuals also expressed a strong interest in using the modeling community at the EPA as a place of collaboration.

The participants in the CREM Workgroup also break into two different groups. One group believes that there is a definite need for an entity such as the CREM to address modeling issues, regardless of how this is done. They believe that the work done by the CREM thus far has been worthwhile. They see the guidance document as long overdue and refer to it as "ground breaking”.

A second group within the Workgroup had a different view. They do not believe that the CREM has the capacity to lead or coordinate the agency on modeling issues, due to lack of resources and expertise. They have the opinion that CREM will therefore not be able to address current and future issues such as integrated modeling in a timely manner. Says one member: "It's one of the reasons that it took ten years to put out the guidance documents, and now they are trying to be a nexus for integrated modeling when 
no one on the staff has the expertise in it” (Interview \# 10, 2009). Individuals in this second group believe that the CREM should stick to its role of facilitation, bringing together the different parts of the modeling community and creating a community of practice. There seems to be no pattern that defines these two groups, each includes members of regional and program offices that are model creators and users.

These differences in opinion about CREM are an interesting paradox because the CREM cannot possibly meet the expectations simultaneously of each group. If the Council focuses singly on its role of facilitator, others will argue for a role of policy creation through documents and products. If they prepare documents to guide and implement policy, they will likely fall behind the pace of model improvements at the agency, appear out of date, and be criticized by those that believe they are taking credit for ideas that are not theirs. I believe that this problem of conflicting role expectations is one of the largest problems that CREM faces today. 


\section{Chapter 5: Conclusions and Recommendations}

\subsection{Conclusions}

EPA’s Council for Regulatory Modeling proves to be an interesting case study in science policy. More specifically, it offers interesting insight into the struggles that are faced when trying to implement science policy within a government agency. Also, since using computer models in decision making activities has become commonplace in many government agencies, the CREM also offers an interesting case study as the first agency program to comprehensively address and provide guidance on environmental regulatory modeling issues. There are a couple conclusions that can be drawn from this case study that are important to the discussion of science policy implementation: 1) organizational structure and behavior of an agency and/or program play an important roles in implementation ability, and 2) some of the implementation impediments faced are paradoxical in nature and have no clear solution.

\section{Organizational Structure}

How an agency is structured will have a large impact on how science policy is implemented. Based on the experiences of the CREM, it is evident that the organization of the EPA does not allow for easy implementation of guidance on modeling. The regional offices present very different environments for implementation than the programs offices. Therefore, the CREM is faced with the challenge of developing and implementing policy that will be beneficial to two very different groups.

The organization of the CREM itself also impedes its ability to implement modeling policy. The CREM has a very limited number of staff and must rely on other 
agency employees in order to be successful. However, this is also an issue that the agency as a whole experiences. EPA employees generally view their organization as under-staffed and believe that most employees do not have time to dedicate to projects that are not directly related to the work required by their management.

\section{Paradoxes}

The CREM faces a few challenges that are paradoxical in nature and do not have clear solutions. Understanding these challenges is crucial to the policy implementation. In order for the CREM to be successful, it has to figure out the best way to balance top down versus bottom up approaches to developing policy. It must be sensitive to the needs and ideas originating from the line staff at the grassroots, while pleasing and still receiving the necessary resources from the top-level administration. This balance is crucial to success in any government agency. Without the proper support from the top, a policy can never be implemented. However, if this support comes with the stipulation that the policy must address what the bureaucracy sees as important rather than what is really happening, the resources will be wasted on policy that is irrelevant. The CREM frequently finds itself in this position.

Also, it is imperative that the CREM find a way to implement the guidance document without initiating hostility from the modeling community. If the guidance document is not successfully implemented, the CREM will have wasted six years on a document that ultimately serves as nothing more than a report on modeling.

Without finding a proper way to handle these problems, the CREM will continue to fall victim to these paradoxical impediments. Since there is no clear roadblock, and 
therefore no clear solution, it is yet another challenge that the CREM faces. It is necessary to find an overarching way to approach these paradoxes as well. If the CREM continues to address them on a case by case basis, they will continue to use up valuable resources that they are already lacking.

\subsection{Recommendations}

The conclusions from this research offer an interesting perspective on implementation of science policy at the "meso" level. The challenges faced by the CREM, more specifically the organizational and paradoxical challenges are similar to what any regulatory agency that utilizes science would confront. My recommendations for addressing these issues are twofold. First, I will examine some possibilities for dealing with general challenges with science policy implementation, and then I will focus more specifically on what the CREM could do to help alleviate their problems.

\section{Science Policy Implementation Recommendations}

The main recommendation for the implementation of science policy overall is to consider the implementation process when developing a policy in the first place. Policies are often reviewed by science advisory committees before being approved, but these reviews are focused on the science and not on the feasibility of implementation. The same pattern is evident in the policy review process - $\mathrm{a}$ focus on content rather than the implementation. The policies themselves need to be developed with the implementation challenges in mind. For example, when the CREM was initiated in 2000, it would have been beneficial for it to consider the organizational structure of the EPA when developing 
the plan for the CREM. How might the differences between regions and program offices affect implementation? Now, the CREM has to try to make the necessary changes to address the differences between the regional and program offices while keeping current with modeling issues. It also would have been beneficial to develop the organization of the CREM with consideration to the different staffing challenges the CREM would face. For example, if the CREM had considered the lack of time that agency employees had, they might have structured the Workgroup quite differently with multiple representatives from each program office to share the workload. Also, when the CREM sought support from the upper administration, they might have requested that the Administrator require participation by Council members. Perhaps if there had been an administrative push to get the Council members involved, the CREM would have an easier time implementing the guidance document. These recommendations would be beneficial for other agencies to consider if they plan to develop a program to provide modeling guidance for their models as well.

\section{CREM Recommendations}

While the above recommendations are relevant to other agencies (and other modeling programs), the CREM is past the stage of policy development, and therefore the above recommendations are no longer appropriate. However, there are still things that the CREM could do to lessen the implementation challenges it still faces. Most of these recommendations come from ideas expressed by interviewees on how the CREM should proceed into the future. 
In terms of facing the organizational challenges, it could be beneficial for the CREM to shift its focus more towards individual model types. For example, workshops or guidance for water modelers would be more beneficial to that group than a general workshop on modeling. This shift in focus could ideally accomplish two things. First, it would help to address the issues created by the EPA organizational structure. The Regional and Program Offices would both benefit from this type of strategy. It would also help to get the workgroup members more involved, thus alleviating some of the burden on the CREM staff. If the workgroup members see that something will directly benefit them, they will be more apt to dedicate their time.

The CREM also needs to regain the top down support that they had in 2002 when the Administrator released multiple memos in support of the CREM. Now would be an excellent time to push for that support since there was a recent change in administration. If the CREM is able to establish some sort of relationship or recognition early on with this administrator, they may have the continued support that they have been lacking.

The CREM has the potential to overcome the many challenges they have faced if they are strategic in their planning. It has been nine years since the Council was established, and they have accomplished more for the modeling community in those nine years than has been accomplished since the EPA was created. They are at a point now where they know the challenges, and the next step is figuring out the best to way approach them in order to successfully implement modeling policy. 


\section{References}

"About EPA" US Environmental Protection Agency. 20 Mar. 2009 < http://www.epa.gov/epahome/aboutepa.htm>.

Andrews, Richard. "Risk-Based Decision Making: Policy, Science, and Politics." Environmental Policy. Ed. Vig, Norman and Kraft, Michael. Washington DC: CQ Press, 2006.

Ashford, Nicholas A. "Advisory Committees in OSHA and EPA: Their Use in Regulatory Decisionmaking." Science, Technology, \& Human Values 9.1 (1984): 72-82.

Compton, Karl T. "Science Advisory Service to the Government." The Scientific Monthly 42.1 (1936): 30-39.

"EPA Organizational Structure" US Environmental Protection Agency. 20 Mar. 2009 < http://www.epa.gov/epahome/organization.htm>

Gilman, Paul. United States. Environmental Protection Agency. Memo to Science Policy Council. Council on Regulatory Environmental Modeling. Washington: GPO, 2002.

Greenwood, Ted. Knowledge and Discretion in Government Regulation. New York: Praeger, 1984.

Jasanoff, Sheila. The Fifth Branch. Cambridge: Harvard University Press, 1990.

McGarity, Thomas O. and Wagner, Wendy E. "Legal Aspects of the Regulatory Use of Environmental Modeling." 10 Environmental Law Reporter (ELI) 10751 (2004)

“Modeling Glossary” EPA Council for Regulatory Environmental Modeling. 9 Oct. 2008. < http://epa.gov/crem/glossary.html>.

National Academy of Sciences. Models in Environmental Regulatory Decision Making. National Academy Press, 2007.

Nederhof, A.J. "Between Accommodation and Orchestration: The Implementation of the Science Policy Priority for Biotechnology in the Netherlands." Research Policy. 19 (1990): 379-386.

Nelson, Norton. Letter to William Ruckelshaus. December 1984.

Pielke Jr, Roger A. The Honest Broker. Cambridge: Cambridge University Press, 2007. 
Pursell, Jr, Carroll W. "The Anatomy of a Failure: The Science Advisory Board, 1933 1935." Proceedings of the American Philosophical Society 109.6 (1965): 342-51.

Rip, A. and Nederhof, A.J. "Between Dirigism and Laissez-Faire: Effects of Implementing the Science Policy Priority for Biotechnology in the Netherlands." Research Policy. 15 (1986): 253-268.

Treasury and General Government Appropriations Act for Fiscal Year 2001. Pub. 106 554. 21 December 2001. Stat. 114 .2763.

United States. Environmental Protection Agency. Science Advisory Board.

Extrapolation Models Subcommittee. Review of Research in Support of Extrapolation Models by EPA's Office of Research and Development. Washington: GPO, 1987.

United States. Environmental Protection Agency. Science Advisory Board.

Environmental Engineering Committee. Resolution on the Use of Mathematical Models by EPA for Regulatory Assessment and Decision-Making. Washington: GPO, 1989.

United States. Environmental Protection Agency. Agency Task Force on Environmental Regulatory Modeling. Agency Guidance for Conducting External Peer Review of Environmental Regulatory Modeling. Washington: GPO, 1994.

United States. Environmental Protection Agency. Science Advisory Board.

Environmental Models Subcommittee. Advisory on the Charter for the Council on Regulatory Environmental Modeling (CREM). Washington: GPO, 1999.

United States. Environmental Protection Agency. Framework for the Council on Regulatory Environmental Modeling. Washington: GPO, 2000.

United States. Government Accountability Office. EPA's Science Advisory Panels: Improved Policies and Procedures Needed to Ensure Independence and Balance. Washington: GPO, 2001.

United States. Environmental Protection Agency. Council for Regulatory Environmental Modeling. Task Order \# 2. Statement of Work, Models for Environmental Decision Making: Principles and Criteria. Washington: 2003.

United States. Environmental Protection Agency. Council for Regulatory Environmental Modeling. Charge to the REM (Regulatory Environmental Modeling) Guidance Review Panel. Washington: GPO, 2005. 
United States. Environmental Protection Agency. Science Advisory Board. REM Guidance Review Panel. Review of Agency Draft Guidance on the Development, Evaluation, and Application of Regulatory Environmental Modeling and Models Knowledge Base by the Regulatory Environmental Modeling Guidance Review Panel of the EPA Science Advisory Board. Washington: GPO, 2006.

Whitman, Christine Todd. United States. Environmental Protection Agency. Memo to All EPA Employees. Strengthening Science at the Environmental Protection Agency. Washington: GPO, 2002.

Whitman, Christine Todd. United States. Environmental Protection Agency. Memo to Administrators and Science Policy Council. Council for Regulatory Environmental Modeling. Washington: GPO, 2003. 


\section{Appendix A - Interview Questions}

Interview Questions for Members of the CREM:

1. How long have you been working with CREM and in what capacity?

2. What do you see as the current goals of the CREM - how have these changed in your time with the CREM? (Why have they changed?)

3. What has the CREM done well, and what do you think it could improve upon?

4. What do you see as the biggest issues with modeling within the EPA? How has the CREM addressed these?

5. What do you see as CREM's biggest strengths and weaknesses?

6. What do you see as the CREM's biggest impediments to success?

7. What do you view as the future role of the CREM? Of modeling at EPA in general?

Interview Questions for Model Creators and User that are Not Members of the CREM:

1. What role would you say you have in modeling (creator, maintain, use, etc)?

2. What do you know about the CREM? Have you ever worked with them, attended a workshop, etc?

3. Are you familiar with the guidance document? How does it affect you and the work that you do?

4. What do you see as some of the biggest issues with modeling throughout the agency?

5. How do you think an entity like the CREM could address these?

6. What could CREM do that would most benefit you and the people that you work with? 


\section{Appendix B - Interview Numbers}

1 - A model creator who is not a member of the CREM

2 - A past and/or present staff member of the CREM

3 - A model maintainer who provides support to users of the model and is not a member of the CREM

4 - A regional representative to the CREM Workgroup

5 - A model creator and user who is not a member of the CREM

6 - A past and/or present staff member of the CREM

7 - An office representative to the CREM Workgroup

8 - A model creator and user that is not a member of the CREM

9 - A regional model creator and user who is not a member of the CREM

10 - An office representative to the CREM Workgroup

11- A past and/or present staff member of the CREM

12 - An office representative to the CREM Workgroup 


\section{Appendix C - EPA Organization Charts}

\section{EPA Organizational Structure}

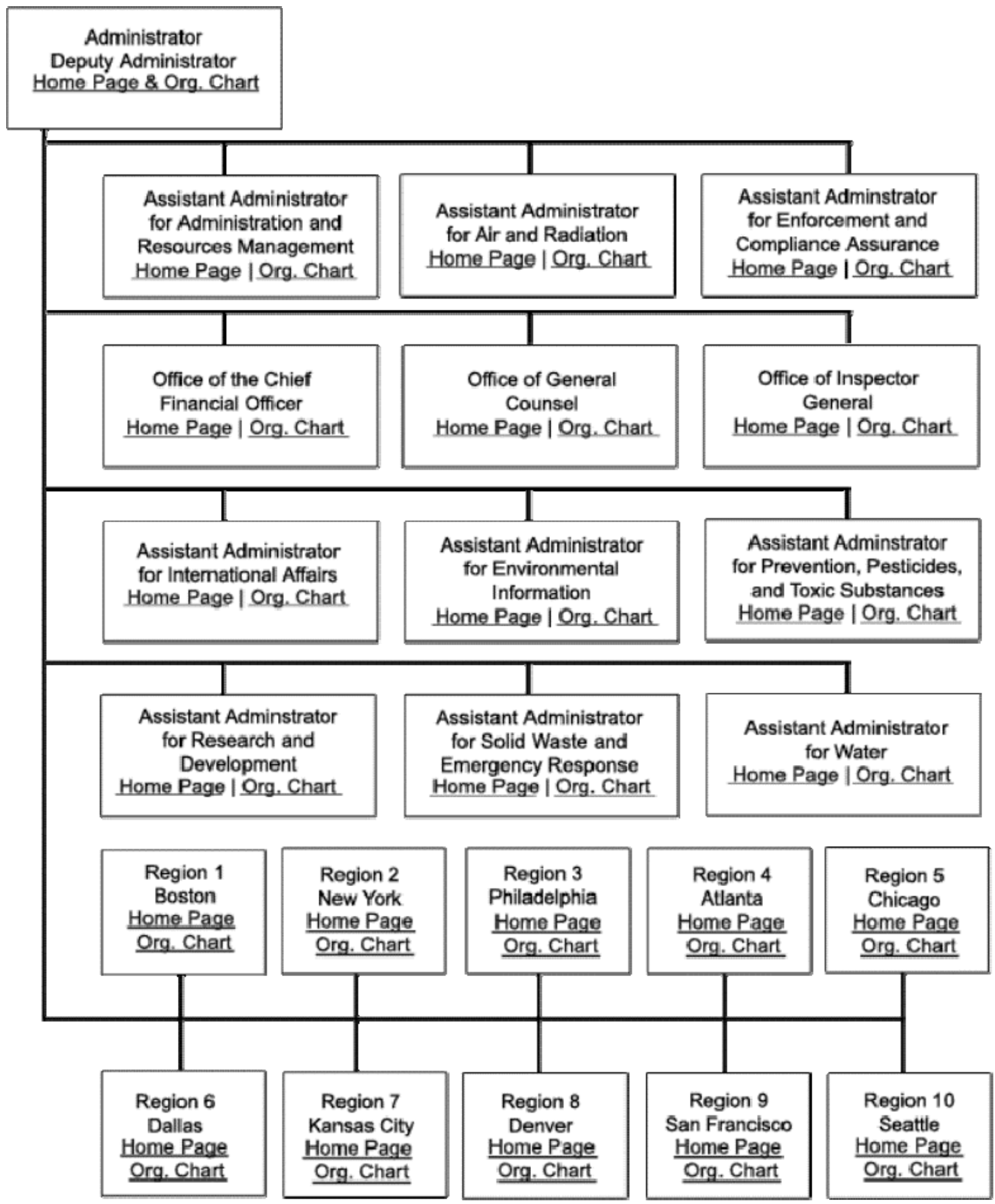

Figure 1 Courtesy of US Environmental Protection Agency

(http://www.epa.gov/epahome/organization.htm Accessed 4/25/09) 


\section{Office of Research and Development Organizational Structure}

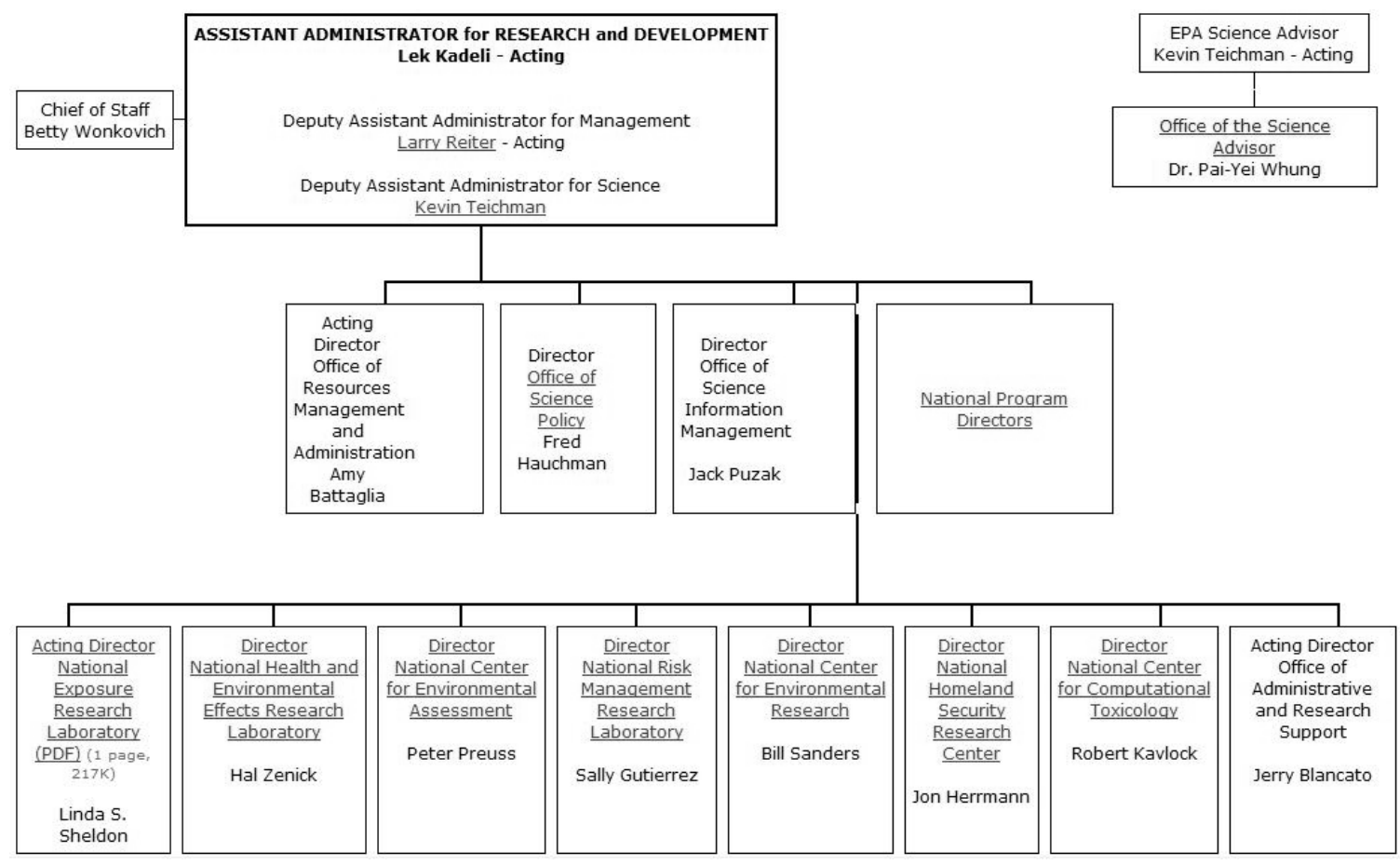

Figure 2 Courtesy of US Environmental Protection Agency (http://www.epa.gov/ord/htm/orgchart.htm Accessed 4/27/09) 


\section{CREM Organizational Structure}

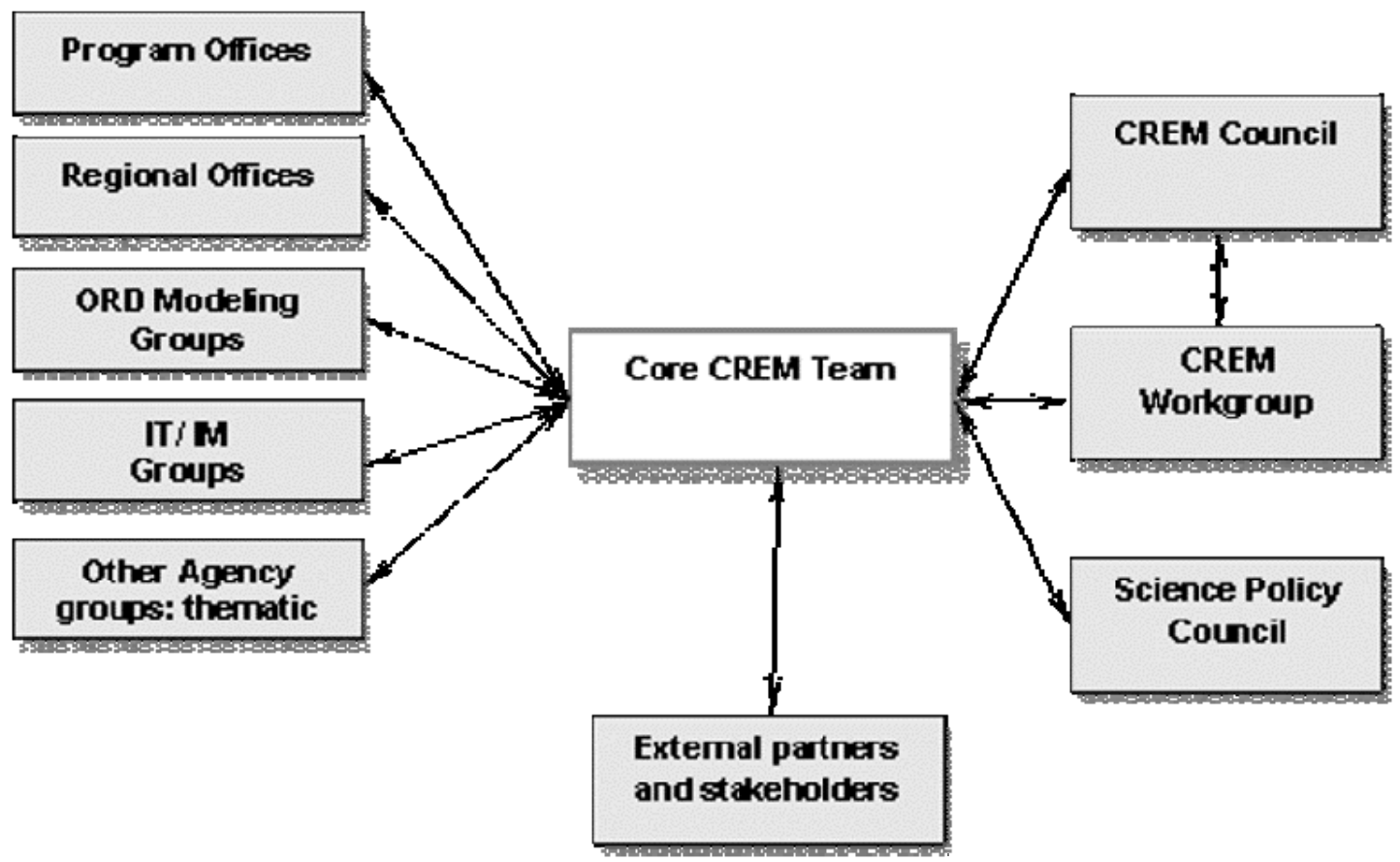

Figure 3 Courtesy of US Environmental Protection Agency (http://www.epa.gov/crem/whoweare.html Accessed 4/25/09) 